\title{
Transforming a flawed policy: A call to revive psychology and science in domestic violence research and practice
}

\author{
Donald G. Dutton*, Kenneth Corvo \\ University of British Columbia, Syracuse University, United States
}

Received 7 October 2005; received in revised form 14 November 2005; accepted 10 January 2006

Available online 10 March 2006

\begin{abstract}
Intimate partner violence (IPV) continues to be social problem in the United States. Unfortunately, legislation aimed at solving the problem has been based on models of IPV that are not empirically supported. One example is "psychoeducational" intervention models legislated by the courts in many states. These models eschew psychological treatment even of empirically established factors supporting habits of intimate abusiveness. They have, in effect, removed a psychology of abusiveness from intervention and replaced it with a gender political model. In contrast to this model, research from several longitudinal peer cohort studies shows that a propensity for IPV is predictable in both genders during adolescence. Yet treatment or prevention of psychological risk factors is either neglected or negatively legislated. This paper reviews the prevailing criminal justice intervention model, provides examples of how the paradigm supporting this model distorts interpretation of research and compares this flawed research with methodologically superior studies suggesting a different and potentially more effective approach.
\end{abstract}

(C) 2006 Elsevier Ltd. All rights reserved.

Keywords: Domestic violence; Criminal justice; Intimate partner violence

\section{Contents}

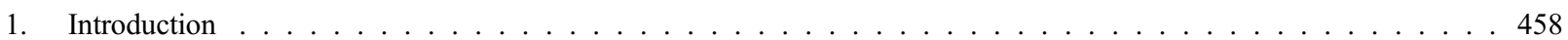

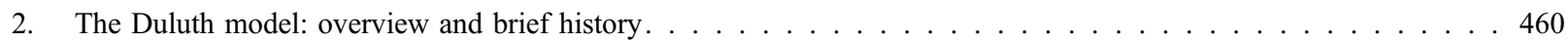

3. Outcome studies of the Duluth model . . . . . . . . . . . . . . . . . . . . . . . . . . . . 462

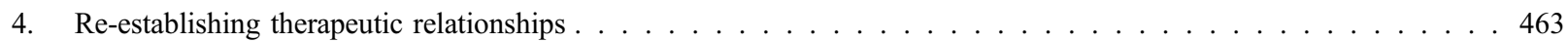

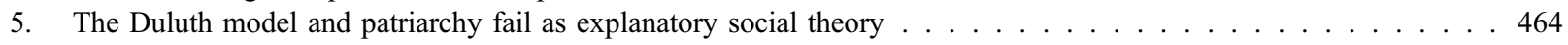

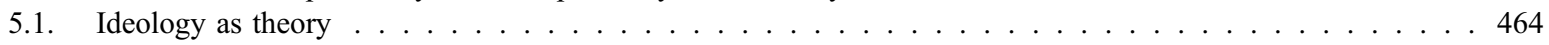

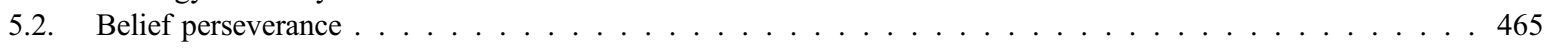

6. Ripple effects of the patriarchal model. . . . . . . . . . . . . . . . . . . . . . . . 468

6.1. Criminal justice practice: does mandatory arrest reduce future assaults? . . . . . . . . . . . . . . . 468

6.1.1. Other legal sanctions. . . . . . . . . . . . . . . . . . . . . . 470

6.2. Impact on custody assessment . . . . . . . . . . . . . . . . . . . . . . 470

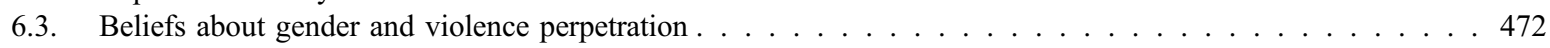

\footnotetext{
* Corresponding author.

E-mail address: dondutton@shaw.ca (D.G. Dutton).
} 


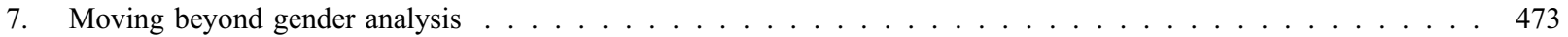

7.1. Meta-analysis of gender differences in aggression . . . . . . . . . . . . . . . . . . 473

7.2. Longitudinal peer cohort studies and the reconceptualizing of female intimate partner violence . . . . . . 474

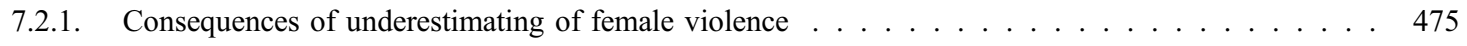

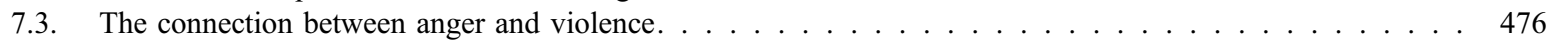

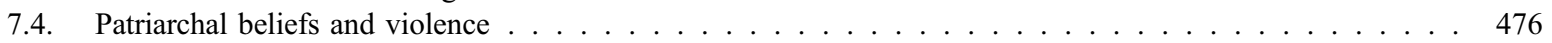

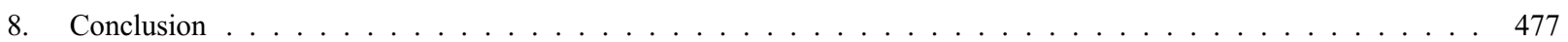

References . . . . . . . . . . . . . . . . . . . . . . . . . . . . . . . . . . . 479

"Any country that has tried to create a political solution to human problems has ended up with concentration camps and gulags." -Erin Pizzey

\section{Introduction}

For over thirty years, the public policy response to the problem of domestic violence has been defined by activists as the socially sanctioned dominance of women by men. This view of patriarchy as the sole cause of domestic violence is the underpinning for a policy/practice paradigm that has dominated the regulatory, legal, and policy discourse of the United States, Canada and other countries (Gelles, 2001; Maiuro, Hagar, Lin, \& Olson, 2001; Mills, 2003). It has influenced legal policy including arrest priorities (Sherman et al., 1992), prosecutorial decision making (Ford \& Regoli, 1993)and post arrest intervention (Maiuro et al., 2001). During the same period, researchers from a variety of disciplines have repeatedly found that domestic violence is influenced by a much wider range of factors (Elliott, 1977; Rounsaville, 1978; Straus, 1973). Violence between intimates and family members stems from a complex of etiological processes with neurological (Dutton, 2001; Meloy, 1992; Schore, 2003a,b), psychological (Dutton, 2002; Dutton \& Holtzworth-Munroe, 1997a,b; Dutton, Saunders, Starzomski, \& Bartholomew, 1994; Dutton \& Starzomski, 1993; Hamberger \& Hastings, 1991; Holtzworth-Munroe, Bates, Smutzler, \& Sandin, 1997; Holtzworth-Munroe, Stuart, \& Hutchinson, 1997), interpersonal (Jacobson et al., 1994; Leonard \& Roberts, 1998; Margolin, John, \& Gleberman, 1989), situational (Eckhardt, Barbour, \& Davis, 1998; Fagan, 1989; Fagan, Stewart, \& Hansen, 1983), and cultural influences (Archer, 2005; Dutton, 1985). The etiology of intimate partner violence has been found to have long term development (Dutton, 2000, 2002) stemming from early family influences such as witnessed violence (Dutton, 2000; Egland, 1993), shaming (Dutton, Starzomski, \& Ryan, 1996; Dutton, Swanson, van Ginkel, \& Starzomski, in press), and trauma (Dutton \& Holtzworth-Munroe, 1997a,b).

Recent evidence from the best designed studies (Ehrensaft, Moffitt, \& Caspi, 2004; Moffitt, Caspi, Rutter, \& Silva, 2001) indicates that intimate partner violence is committed by both genders with often equal consequences (Laroche, 2005; Pimlott-Kubiak \& Cortina, 2003; Serbin et al., 2004). The violence is not committed because of "sex role beliefs" but formation into an intimate abuser begins developmentally much sooner, from a much broader array of psychosocial risk (Dutton, 2002; Putallaz \& Bierman, 2004; Serbin et al., 2004; Sroufe, Egeland, Carlson, \& Collins, 2005).This occurs in both genders (Dutton, 2002, 2001). Personality disturbance and behavioral features in fifteen year old girls predict their use of violence in relationships at age 21 independent of violence usage by a male partner (2001).

Recurring intimate partner violence (IPV) is most frequently sustained by interactive factors (Leonard \& Senchak, 1993; Levenson \& Gottman, 1983; Margolin et al., 1989; Stets \& Straus, 1992a,b) and bilateral violence is the most common form of IPV; the stereotype of male perpetrator-woman victim is the least common form (Stets \& Straus, 1992a,b). Left without state intervention, most violent marriages de-escalate rather than escalate (Feld \& Straus, 1990) and state intervention in the form of mandatory arrest has differentially effective impact on different populations as function of their marginality in the social fabric (Sherman et al., 1992). Even summed across all groups the ability of arrest to depress recidivism is slight and limited to about 8 months (Sherman et al., 1992).

In spite of numerous studies identifying these psychological risk features for both genders, many US states and Canadian provinces remain rigidly locked into outmoded and poorly informed policies. For example, prohibited practices in Georgia include any therapeutic intervention involving linking "causes of violence to past experiences," "communication enhancement or anger management," systems theory and addiction counseling models (Georgia, 
2002). Similar prohibitions exist in many states (Healey, Smith, \& O'Sullivan, 1998; Maiuro \& Eberle, in press). In short, any practice that could be construed as psychological treatment is prohibited. Instead these states legislate a variant of a "psychoeducational model" that originated in Duluth, Minnesota and is called the Duluth Model. The primary goal of this model is to get male clients to acknowledge "male privilege" and how they have used "power and control" to dominate their wives. Many men coming to court-mandated therapy feel no sense of power and control in any arena of their lives, including their marriage (Dutton \& Starzomski, 1994). Hence, not only is a political model mapped onto intervention, but the model commits the primary mistake of therapy: to not acknowledge the client's reality.

Why have professional associations such as the American Psychological Association and the National Association of Social Workers not taken a public position on this issue acknowledging the lack of scientific support for these practices? Psychology has a long-standing tradition, dating back to the Boulder Model, of basing practice on research data that indicates the most effective practices. This is nothing more than common sense pragmatism. Why then are psychologists not doing that in intimate partner interventions? Why are we not doing assessments to establish: 1) the interactive form of the couples' violence, 2) the power dynamic in the couple, 3) the lethality potential in the couple, and 4) the best fit between treatment and client profile? Instead, a "one size-fits all" approach, based on a contraindicated political model of male domination prevails. Evidence-based practice, under a variety of rubrics, has becoming established in psychology, social work, medicine, and other professions as the guiding framework for effective treatment, yet the Duluth model remains intact in the face of extensive contradictory evaluation findings.

Evaluation research on interventions for domestic violence perpetrators based in the Duluth model shows no methodologically sound evidence that these programs significantly change violent behavior. To the contrary, several experimental outcome studies yielded an effect size of zero (Davis, Taylor, \& Maxwell, 1998; Feder \& Forde, 1999; Levesque, 1998; Shepard, 1987), yet this model is mandated in many states as the only acceptable form of intervention. Forty-three states have set up domestic violence certification agencies to oversee the "intervention" with abuse perpetrators (2001). These agencies, often staffed by political appointees and activists, have formulated and applied policies that regulate not only the conditions of probation for persons found guilty of domestic assault but also which form of intervention is deemed acceptable by the courts. Hence, program funding is only available to those programs that conform to these policies, called interventions (using "batterer accountability" strategies) instead of "treatment" because the Duluth model deems assault to be a willful exercise of male privilege, a choice made by men acting in concert with the norms of a sexist society. In this view, poverty, stress, chemical dependency, anxiety, deficits in selfesteem or the man's own lifetime experience of victimization are never risk factors for male abuse perpetration. It is never influenced by an also violent wife or partner, or by a relationship where substance abuse or personality disorders may occur in the perpetrator, victim, or both. At least this is so for male violence, female violence, to the extent that is acknowledged at all, is deemed to be always self-defensive. (Dobash \& Dobash, 1979; Saunders, 1988) These beliefs persist, despite considerable evidence to the contrary, including both survey data showing approximately equal levels of severe violence and injury by gender (Archer, 2000; Laroche, 2005) and the fact that several large longitudinal studies in age cohorts show equal abuse perpetration by gender with roughly equal results in terms of physical injury (Ehrensaft et al., 2004; Magdol et al., 1997) or psychological trauma (Pimlott-Kubiak \& Cortina, 2003).

Although some critics have disparaged the instrument of measurement, the Conflict Tactics scale or CTS (Straus, 1992), in fact this scale is 16 times more sensitive than government "crime victim" surveys (Straus, 1999) such as the National Violence Against Women Survey (Tjaden \& Thoennes, 1998). These surveys, in turn, tend to filter out male reports of victimization because of the "set" of the survey (criminal victimization of women). When this set is altered, more equivalent rates of violence are reported, as in the Canadian General Social Survey of 25,876 respondents, equally split by gender. In this survey (Laroche, 2005) the "crime victim" filter was dropped and the focus was on "perceptions of crime". In addition, men were asked about instrumental controlling behaviors used against them, (Laroche, 2005) something that had not previously been asked because of the assumptions of the patriarchal paradigm. Equivalent rates of severe abuse were found, $8 \%$ of women, and $7 \%$ of men reporting victimization. Use of repeat, severe instrumental violence by a partner was reported by $2.6 \%$ of men and $4.2 \%$ of women. Equivalent injuries, use of medical services and fear of the abuser were also discovered in cases where the abuser used repeat instrumental abuse. Why is this small but destructive sub-group not receiving a concentrated intervention strategy? Instead, they are mixed with less serious cases in a "drift net" approach.

Stets and Straus (1992a,b) combined the 1985 US National Family Violence Resurvey $(N=5005)$ with a sample of 526 dating couples to generate a large and representative sample of male-female relationships, in which they 
reported incidence of intimate violence by gender. Using a subset of 825 respondents who reported experiencing at least one or more assaults the authors found that in $1 / 2(49 \%)$ of the incidents the couples reported reciprocal violence, in $1 / 4(23 \%)$ of the cases the couples reported that the husband alone was violent and $1 / 4(28 \%)$ reported the wife alone was violent. Men $(n=297)$ reported striking the first blow in $43.7 \%$ of cases and that their partner struck the first blow in $44.1 \%$ of the cases. The women $(n=428)$ reported striking the first blow in $52.7 \%$ of the cases and that their partner struck first in $42.6 \%$ of the cases. Stets and Straus $(1992 \mathrm{a}, \mathrm{b})$ concluded that not only do women engage in a comparable amount of violence, they are "at least as likely" to instigate violence. The results also indicated that women were more likely to hit back $(24.4 \%)$ than men (15\%) in response to violent provocation by a partner (Straus \& Gelles, 1992). This latter result is difficult to explain from the patriarchal view that women are more afraid of male violence than the reverse. Stets and Straus also analyzed for level of violence $\times$ gender. They concluded that equal levels of violence by both men and women were the most common form of violence ( $40 \%$ of married couples). The second most frequent form was women using severe violence against men who were either completely non-violent or who used only minor violence (about $16 \%$ of married couples). The stereotypical pattern (male severe, female none or minor) was found for only $8 \%$ of married couples. The greater frequency of a female severe pattern was even more pronounced in cohabiting couples (19\% vs. $8.5 \%)$ and dating couples (26\% vs. 5\%). These data were first published in 1989. Most professionals are still unaware of these data patterns. In fact, in many states a court-mandated "intervention program" that specifically eschews psychological treatment is in place, based on the notion that interpersonal partner violence is a form of gender oppression akin to slavery (Pence \& Paymar, 1993). "Facilitators" are advised to use the slavery model in "raising consciousness" of clients and any mention of mutual violence is treated as "victim blaming," despite its having some statistical likelihood. The APA Website, Public Information Directorate provides an executive summary of the 1996 APA Presidential Taskforce on Violence and the Family. The "public information" provided includes the following on the first page: "Men batter women far more frequently than women batter men. Boys who witness or experience violence in their own homes as children are at major risk for becoming batterers"....and "Approaching the forms of family violence as a unified field of study underscores the common dynamic at the heart of them: the perpetrator's misuse of power, control, and authority" (www.apa.org/pi/viol and fam.html). Hence the notions that family violence is primarily male perpetrated and based on "power and control" are offered in the APA's own website.

\section{The Duluth model: overview and brief history}

Established in 1981, the Duluth Domestic Abuse Intervention Project (DAIP) designed an intervention program to be applied to men who had assaulted their female partners but who were not going to receive jail time. The objective of the program was to ensure safety of the women victim (protection from recidivist violence) by "holding the offenders accountable" and by placing the onus of intervention on the community to ensure the woman's safety. The curriculum of the Duluth model was developed by a "small group of activists in the battered women's movement" (Pence \& Paymar, 1993) (including representatives from EMERGE in Boston, op.cit. p. viii) and was designed to be used by paraprofessionals in court-mandated groups. It is now one of the most commonly used court-sanctioned interventions for men convicted and having mandatory treatment conditions placed on their probation. This is true in many U.S. states and Canadian provinces. The curriculum of the model stresses that violence is used as a form of "power and control" and a "Power and Control Wheel" has become a famous insignia of the program. Also, power and control is seen as being an exclusively male problem. As the authors put it "they are socialized to be dominant and women to be subordinate" (p. 5, all quotes are from Pence and Paymar (1993)). Hence, the "educational" aspect of the program deals with male privilege that exists in patriarchal structures such as North American countries. The DAIP view of female violence is that it is always self-defensive; in fact, can only be self-defensive. "Women often kick, scratch and bite the men who beat them, but that does not constitute mutual battering" (p. 5). Male battering stems from beliefs which are themselves the product of socialization. These include the belief that the man should be the boss in the family, that anger causes violence, that women are manipulative, think of men as paychecks, if a man is hurt, it is natural for him to hurt back, smashing things is not abusive, "women libbers" (sic) hate men, women want to be dominated by men, men batter because they are insecure, a man has the right to choose his partners' friends and associates and a man cannot change if the woman will not (p. 7-13). According to the manual, the basis for these beliefs came from a sample of 5 battered women and 4 men who had completed the Duluth program. This then became the empirical foundation of domestic violence practice: a sample of nine clients recently completing an ideologically infused intervention. The 
authors (and those who support this model) apparently do not realize the obvious problems with the samples' small size or lack of representativeness.

The Duluth model focus on power and control ${ }^{1}$ obliges men to keep "control logs" and review the socialization that leads to expectations of "male privilege." It "discusses how making women into sex objects and then defining sex objects as bad degrades women and lowers their self-esteem. From there it goes on to discuss why men would want women to have low self-esteem" (p.41). It does not address any psychological issues or emotions that group members may have. "Negative feelings" are seen as caused by patriarchal beliefs (p. 48). Instead, it focuses on patriarchy, including drawing a pyramid on the board and asking "who is at the top"? and how did he get there? (p. 43). The facilitator is advised to use slavery or a colonial relationship as an example to "draw a picture of the consciousness of domination" (p. 49) (Pence \& Paymar, 1993). The Duluth model uses role plays to show male abusiveness (p. 61) and raises men's consciousness about trivializing women's anger (p. 62). Men are encouraged to "respond in a respectful way" (p. 63) when their female partner gets angry. Any and all risk factors for IPV (stress on the perpetrator, impulse control problems, trait anger, communication skill deficits, couples negative interaction, personality disturbance, inter alia) are dismissed as "excuses."

The major goals of the Duluth model (respectful and non-abusive relationships) do not differ from those of other theoretical models of intervention for abusive men (such as Cognitive Behavioral Therapy or even psychodynamic treatment) or from the goals of more general mainstream psychosocial treatments. However, the means to the end differs significantly from psychological and family systems models that have been proven to be more effective than the pure Duluth model (Babcock, Green, \& Robie, 2004). The primary difference seems to be in their unyielding adherence to their etiology of violence, their monolithic model of male domination and instrumental violence taken as a given and the emphasis on socialization and control of women to the exclusion of other factors contributing to abuse and of subtypes of abuse perpetrators. This ideologically narrowed view of domestic violence distorts and limits other approaches to behavioral and psychological change and generates an atmosphere in the client group that cannot be conducive to honest exchange, vulnerability, trust or disclosure. Rather, judgment and humiliation is the central feature of these groups, as the result can only be grudging compliance in clients who wish they were elsewhere, or high dropout rates; $75 \%$ in one program (Davis, Taylor, \& Maxwell, 2000).

The Duluth perspective on psychological problems is also outlined in their manual "Most group members are participating not because of a personal of family dysfunction but rather because violence is a socialized option for men. To attach a clinical diagnosis to the batterers' use of violence provides a rationalization for behavior that may not be accurate" (p.23).(Pence \& Paymar, 1993) In the rare case where "mental illness" is diagnosed, other treatment is recommended.

The Duluth model imbeds its perpetrator intervention strategies within a framework called "Coordinated Community Response" (CCR) (http://www.duluth model.org/documents/catalogue.pdf). The CCR seeks to bring the ideological assumptions underlying the Duluth model to law enforcement, criminal justice, human services, and other sectors of the community. As a general strategy, coordinating services at the community level is often a method of avoiding duplication and maximizing resources. The CCR of the Duluth model, however, maintains an ineffective system where resources are diverted from other potential program responses (e.g., joint treatment of violence and chemical dependency or mutuality of partner violence).

The problem, in a nutshell, is that according to the model's proponents a political model (a radical form of feminism) is incongruent with psychological and biological models. The Duluth model avoids utilizing the term "therapy" because therapy implies there is something wrong with clients, whereas, according to the Duluth philosophy they are normal, simply following cultural dictates. Our belief is that psychological, biological and social/political factors are not inherently incongruent but rather co-exist in a four-level "nested ecological" framework (Dutton, 1985). The research to date suggests that if we want to develop effective models of intervention for domestic violence, we must consider all levels with perpetrators, victims and witnesses.

\footnotetext{
${ }^{1}$ Dutton (1994) pointed out that men in treatment groups were more often characterized by powerlessness than by power and that the concept of power was misused by feminism. Power as a motive can be manifested through seeking political office, stamp collecting, or becoming a serial killers' girlfriend (McClelland, 1975). It refers to any activity that enhances the self. Hence, Walker's inappropriate discussion of the "androcentric need for power" (Walker, 1989) views only those power enhancing activities believed to be used more frequently by males, the ones McClelland called "type 3" power orientations. Feminist theory seemed unaware of the broader manifestations of the psychological power motive. Most people seek to have "power and control" in their lives, the feminist focus is on the more specific application of "power over" another person.
} 


\section{Outcome studies of the Duluth model}

The Duluth model's negligible success in reducing or eliminating violence among perpetrators in tandem with the iron-grip of prohibition of other approaches is perhaps its most damaging feature.

In a treatment outcome study done on the Duluth model, Shepard $(1987,1992)$ found a $40 \%$ recidivism rate in a six month follow-up of Duluth clients, higher than most control recidivism levels. Babcock et al. (2004) put recidivism rates at $35 \%$ for a $6-12$ month follow-up according to wives, and $21 \%$ for the same time period using criminal justice data (arrests).

Feder and Forde (1999) randomly assigned perpetrators on probation to either a feminist-psychoeducational program or no treatment in Broward County, Florida. In general, there were no statistically significant differences between the two groups on recidivism as measured by police records $(d=0.04)$ or by victim report $(d=-0.02)$. There was a small but significant effect on recidivism among the subset of men randomly assigned to group treatment who attended all 26 sessions. In this study, random assignment apparently failed, with an uneven number of men being assigned to the treatment and control condition (Feder \& Forde, 1999). Moreover, this study suffered from a particularly high attrition rate of men from treatment $(60 \%)$ and low response rate from victims at follow-up (22\%) (Feder \& Forde, 1999).

In a large evaluation of U.S. Navy personnel stationed in San Diego, Dunford (2000) compared a 36-week cognitive-behavioral group and a 26-week couples therapy format to a rigorous monitoring condition and a notreatment control (victims safety planning). Neither CBT men's groups $(d=0.13)$ nor couples therapy $(d=0.10)$ had a significant impact on recidivism at one-year follow-up based on victims' report. This study represents the most methodologically rigorous study conducted to date in terms of sample size, length of follow-up, attrition rates, follow-up reporting rates, and assessment of treatment adherence. However, it is important to note that this sample of perpetrators, those employed through the Navy in San Diego, are not representative of the population of perpetrators court-mandated to domestic violence programs around the country. All of the research participants were employed, had a high stake in social conformity, and thus, were more "socially bonded" (Sherman et al., 1992). Any intervention, including arrest and being identified by authorities, may work to deter socially bonded individuals from repeat offenses. This may be reflected in the unusually low official recidivism rates of the nontreated perpetrators $(4 \%)$.

Davis et al. (1998) compared a long (26-week) psychoeducational group to a brief (8-week), psychoeducational group, and to a community service control in Brooklyn, New York. They found a statistically significant reduction in recidivism and a small but respectable effect size of $d=0.41$ based on criminal records among the long treatment group only; the 8 -week group was indistinguishable from the community service control $(d=0.02)$. When based on victim reports of recent offenses, neither the long nor the brief intervention had a statistically significant effect on recidivist assault when compared to no treatment. Correspondingly, the effect size due to treatment based on partner report of subsequent violence was small $(d=0.21)$. It is important to note that, like in the Broward County experiment (Feder \& Forde, 1999), random assignment may have been compromised. In the Brooklyn experiment (Davis et al., 2000), nearly $30 \%$ of initial assignments were subjected to "judicial overrides" that is, judges reassigned defendants to different interventions.

Ford and Regoli (1993) designed a study that randomly assigned perpetrators into treatment as a pretrial diversion (i.e., defendants' criminal records would be cleared pending treatment completion), treatment as a condition of probation post-conviction, vs. alternative sentencing strategies (e.g., paying a fine or going to jail). Even though this study was designed to test different sentencing options rather the effects due to treatment, one can compare perpetrators sentenced to treatment vs. perpetrators not sentenced to treatment (although the type of treatment and actual attendance rates were not specified). Again, there were no significant differences or effect sizes comparing recidivism rates based on victim report between men sentenced to treatment vs. those who were not. Neither treatment as pretrial diversion $(d=0.00)$ nor as a condition of probation post-conviction $(d=-0.22)$ was found to be superior to purely legal interventions.

Babcock et al. (2004) conducted a meta-analytic study of 22 studies of treatment outcome. The $d$ ' for Duluth treatment was .19. Comparisons between CBT and Duluth were not significant but "pure" Duluth models were hard to find. As the authors state "modern batterer groups tend to mix different theoretical approaches to treatment, combining feminist theory of power and control as well as specific interventions that deal with anger control, stress management and improved communication skill” (p. 1045). 
While "treatment" of anger, interactive issues and other psychological issues may infiltrate the approach of frustrated treatment providers, the rapproachment of blending Duluth and cognitive behavioral treatment philosophies is stymied by the issue of therapeutic bonding. In other words, Duluth aspects of blended groups work against therapeutic bonding which is necessary for treatment success (Luborsky, 1984; Schore, 2003a,b). The best results in the Babcock et al. study were found for "pure" CBT programs.

There is nothing in the evaluation research on domestic violence treatment outcomes that justifies mandatory Duluth-type programming. On the contrary, there is a distinct absence of evidence for their efficacy. Often, the safety of victims is used as a rationale for mandating Duluth-type interventions. It is difficult to imagine how the safety of victims is improved by programs with negligible impacts on the violent behavior of their partners. Despite these data, here is what the APA Website says about mandatory treatment: "Psycho-educational models that are cognitively and behaviorally oriented seem to be most effective in helping many offenders stop their physical violence" (www.apa.org/ pi/issues/issie10.html).

Because of the assumed ideological infallibility of the Duluth model, the kinds of program quality, clientsatisfaction, "customer" driven analyses of other kinds of programs are not critically explored. Contrast, for example, the detail and openness in the following review of psychosocial interventions for substance use disorders with the statements from a domestic violence agency ad seriatum:

"Between $7 \%$ and $15 \%$ of patients who participate in psychosocial treatment for substance use disorders may be worse off subsequent to treatment than before.. Probable person-related predictors of deterioration associated with treatment include younger age and unmarried status, more serious current diagnoses and substance use problems and more psychiatric and interpersonal problems. Probable intervention-related predictors of deterioration include lack of bonding; lack of monitoring; confrontation, criticism and high emotional arousal; deviancy modeling; and stigma, low or inappropriate expectations and lack of challenge” (Moos, 2005).

This kind of self-appraising orientation to treatment is made impossible by this sort of program rhetoric: "Battering is never.... provoked, hereditary, out of control, accidental, or an isolated incident with no further dynamics. Battering is not caused by disease, diminished intellect, alcoholism/addiction or intoxication, mental illness or any external person or event. Domestic violence is a means for men to systematically dominate, control, devalue and disempower women. Battering/violence is greater than an individual act; it supports the larger goal of the oppression of women. Men batter because they can and it serves as a means to an end." This quote was from a "health counseling" presentation in New York State (Corvo \& Johnson, 2003). No other circumstances, motivation, or interpretations are permitted. With this mindset, high levels of program attrition are inevitable. No therapeutic bond can form and clients who comply will feel judged and disbelieved. Empathy is impossible, change is unlikely, group process is subverted, and clients' commitments to change are rarely internalized. It is a "take it or leave it" posture and many clients do just that: leave. Approximately $40-60 \%$ of men attending the first session of treatment actually fail to complete Duluth model-type treatment in spite of participation often being a condition of probation and failure to comply risks incarceration (Buttell and Carney, 2002).

\section{Re-establishing therapeutic relationships}

Dutton (2003) argued that Duluth models had two major flaws that were contraindicative of effective treatment; they attempted to shame clients and, in taking a strong adversarial stance to clients (based on a view of male sex role conditioning as a major issue in domestic violence), failed to establish a therapeutic bond with their clientele.

The single most predictive factor for successful therapeutic outcome (even those labeled "interventions") is the therapeutic bond (Schore, 2003a,b; Sonkin, 2005). However, it becomes extremely difficult to form a positive relationship when the therapist is required to assume that strategic intentional domination is the sole motive for all clients and to presumptively disbelieve any claims of mutuality raised by clients (whether legitimate or not). Treatment providers in many states may not be certified or can lose their certification for court-ordered treatment if they do not confront their clients even in relationships where abuse is mutual (Healey et al., 1998). Since, one must balance confrontation with support, belief and caring in order to develop a solid therapeutic alliance. Building a therapeutic alliance without colluding with dangerous acting out behaviors is one of the greatest challenges facing domestic violence perpetrator treatment providers. Because so many of these individuals experienced abuse by authority figures, the process of building a trusting relationship is particularly difficult. 


\section{The Duluth model and patriarchy fail as explanatory social theory}

How do the Duluth model and its ideological assumptions fare as explanatory social theory regarding domestic violence? Social theory can be evaluated according to a set of epistemological principles. These evaluative criteria have been consistently identified in various formats, e.g. Dubin (1978), Monet, Sullivan and DeJong (2005) and Reynolds (1971). The patriarchal view of domestic violence fairs poorly when assessed against these criteria of sound social theory:

a. How well does the theory generate hypothetical statements that can be empirically tested?

b. How well does the theory predict relevant events, characteristics, or circumstances?

c. How well does the theory explain variation in the phenomena observed?

d. How well does the theory fit with known empirical data?

e. How well does the theory provide a sense of understanding of what causes events, characteristics, or circumstances?

f. How well does the theory generate effective intervention and prevention approaches?

\subsection{Ideology as theory}

The development of theory as a model for understanding a particular area of knowledge is necessarily bounded and hence excludes realms of phenomena. What is excluded, however, may include crucial variables that would improve the precision of prediction. The Duluth model has over-simplified the range of domestic violence phenomena it addresses in order to better understand and address that limited range of phenomena.

The theoretical deficits of the patriarchal model have been explored above and in other papers (Archer, 2000; Corvo \& Johnson, 2003; Dutton, 1994). Simply put, the evidence for theoretical patriarchy as a "cause" of wife assault is scant and contradicted by numerous studies: male dominant couples constitute only $9.6 \%$ of all couples (Coleman \& Straus, 1985); women are at least as violent as men (Archer, 2000); women are more likely to use severe violence against nonviolent men than the converse (Stets \& Straus, 1992a,b); powerlessness rather than power seems related to male violence; there are data contradicting the idea that men in North America find violence against their wives acceptable (Dutton, 1994; Simon et al., 2001) and that abusiveness is higher in lesbian relationships than in heterosexual relationships (Lie, Schilit, Bush, Montague, \& Reyes, 1991) suggesting that intimacy and psychological factors regulating intimacy are more important than sexism (Dutton, 1994). The research evidence has not favored the simplistic patriarchal view of domestic violence: that male intimate violence is a form of gender political suppression. Using "slavery" as a model when men are dominant in families $9.6 \%$ of the time is sheer folly. Were only $9.6 \%$ of white slave owners dominant? Studies such as the Archer (2000) meta-analytic combination of numerous studies with a combined $n$ of 60,000 found women to be more violent than men, especially among younger women. In fact, only about $3 \%$ of all males (and about $1 / 3$ of males in court-mandated treatment) fit the stereotype of terrorist violence put forward by the Duluth model (Dutton, in press; Dutton \& Nicholls, 2005). Many males will be arrested who come from families where violence is dyadic, minor, or female perpetrated (Stets \& Straus, 1992a,b). According to the Duluth model, all must be treated as patriarchal terrorists regardless of differences how the violence developed.

It is not that perpetrators described by the patriarchal view of domestic violence do not exist, it is that they represent a small segment of the range and patterns of perpetration. It would be the theoretical equivalent of viewing anyone who used any illegal drugs or any amount of alcohol above acceptable social levels as a long term heroin or crack cocaine addict. Further, substance abuse, dependency, and addiction would all be products of a single moral weakness.

The awareness among policy-makers and researchers that the Duluth model creates a divide between pertinent research on violence and aggression and domestic violence practice is not new. For example Fagan (1996) stated: "Yet theory and research on domestic violence have segregated theories of violence from theories of battering. The social and ideological constructions of battering have limited the types of variables considered in research on domestic violence. Assuming that patriarchy and power relations alone cause domestic violence leads us toward conclusions that do not consider a full array of explanatory variables from other disciplines" (Fagan, 1996).

As a by-product of the group polarization underlying the Duluth model, the stereotyping of males and even assaultive males leads to his one-size fits all approach (Corvo \& Johnson, 2003). Essentially, the Duluth model views every man convicted as equivalent to the worst man convicted without gradations or nuance. In some cases the assault is trivial, yet it is viewed as a prelude to an inevitable escalation to "battering", despite evidence that shows de- 
escalation is far more likely (Feld \& Straus, 1990). Furthermore, scientific studies repeatedly show that many different types of abusive male and abusive couples exist but their heterogeneity is reduced by the monolithic view maintained by the Duluth model (Hamberger, Lohr, Bonge, \& Tolin, 1996; Holtzworth-Munroe \& Stuart, 1994; Tweed \& Dutton, 1998). In many states, treatment of the psychology that may drive male abusive behavior (e.g., inordinate jealousy stemming from attachment problems and exposure to early trauma) is specifically eschewed, as is treatment of the man's anger, communication deficiencies, couple interaction problems, impulse and emotional regulation deficiencies. There is a lengthy scientific literature that implicates all of these as features of abuse that increase the risk for abusive behavior, so, ipso facto, if they are treated properly by a psychologist, social worker, or family therapist, abuse should diminish.

The politically based interventions mandated by states following the Duluth model, present mental health professionals with a dilemma: do they attempt to provide a form of treatment that could be considered a form of malpractice when viewed through their own codes of ethics and requirements for professional licensure?

If then the patriarchal view underlying the Duluth model fares so poorly as social theory, why does its influence persist? Put simply, it is not a theory; it is an ideology. Turner's (1986) distinction between science and ideology is useful here. Ideologies seek knowledge to confirm how the world ought to be, not how the world is. Therefore information that does not conform to adherents' views of how the world ought to be is excluded from consideration. Further, criticism or contradiction of scientific findings is an inherent (if not always appreciated) component of knowledge-building. Ideology, on the other hand, prohibits contradiction and criticism and views them as betrayal.

\subsection{Belief perseverance}

Maintaining the conviction that patriarchy is THE cause of IPV constitutes a form of belief perseverance. The first principle (male perpetrator, female victim) is unquestionable, all contradicting evidence is rejected for not adhering to the first principle, and, once accepted, all subsequent considerations must conform to the first principle. Many of the inaccurate assumptions embedded in the Duluth model have been so often repeated and so widely assumed that they seem to be true. Social psychologists have shown how people (and groups) ward off disconfirming data to sustain important beliefs. Lord, Ross and Lepper (1979) showed how subjects would disparage research methodology when the research findings contradicted their own. The feminist attach on the CTS/CTS2 is a social science version of this phenomenon (see also Dutton \& Nicholls, 2005). Janis's (1982) notion of "groupthink" showed how groups with a shared ideology and sense of moral superiority would enhance this phenomenon. In this section we review some of the types of epistemological legerdemain that have been used to obscure gender symmetry in violence use. The interested reader should examine the works of proponents of the feminist view (Bograd, 1988; Dobash, Dobash, Wilson, \& Daly, 1992; Kimmel, 2002).

Research methodology, instead of serving as buffer against "Type 1 error," has been used to artificially inflate "evidence" for a political position. Dutton and Nicholls (2005) referred to this as the "gender paradigm" and claimed it acted to shape research focus and ward off disconfirming results. One was of doing this is through defining variables in overly inclusive or misleading ways. Feminist ideology sees socio-structural "patriarchy" acting through individual men via negative attitudes toward women and positive towards use of violence. No explanation is given for individuals' differences. Definitions of attitudes accepting of violence are often misleading. For example, Hanson, Cadsky, Harris and Lalonde (1997) administered questionnaires to 780 men from a forensic out-patient clinic and 217 men from a community based employment center, assessing personal history, criminal behavior and "attitudes towards violence." The sample was divided into 184 non-abusive men (based on self-report), 517 moderately abusive and 296 severely abusive. The variable called "attitudes tolerant of wife assault" was defined as follows: "An unfaithful wife deserves to be hit," "I might slap my wife to make her listen," "I could slap my wife to stop her being hysterical," "I might slap my wife if she made me really angry." The authors then did linear comparisons on 53 variables in order to find which ones differ significantly between groups. They concluded, "The single strongest group difference concerned attitudes tolerant of wife assault. Most (68\%) of the severely abusive men endorsed one or more of the items on the scale, whereas only $22 \%$ of the non-abusive men endorsed any items." There are some serious flaws in this study: the attitude measures are worded so they are predictions of a likelihood of violence; "I might slap my wife if...." For "severely abusive" men, these are not indicative of tolerance of abuse they are merely accurate predictions of likelihood of one's own behavior. These men indicated some accuracy in describing how they might react. Therapists usually 
want their clients to have this ability to see themselves as high risk in certain situations. Then they can be more vigilant in those situations.

Smith (1990) also tested "patriarchal beliefs" by asking female respondents to estimate their partner's response to a series of four questions tapping this attitude and then correlating the projected attitude with her reports of his violence on the CTS. (No women were asked about their own use of violence). Smith argued that he was assessing "patriarchal ideology" but the responses supplied looked predominantly non-patriarchal. The women said their partners would disagree with a man has a right to decide 1) whether his partner has a right to work outside the house $(64 \%), 2)$ whether she should go out for the evening $(68 \%)$ and 3$)$ whether to have sex without a consenting partner $(80 \%)$. The only statement that did not get a majority disagreement was "sometimes it's important for a man to show his partner that he's head of the house" (47\%). The women also said that $90-96 \%$ of their husbands would not approve of violence towards them. Even if he learned she was having an affair or she hit him first, the majority (75\%) said he would not approve of violence. The most obvious conclusion from Smith's data would be that "patriarchal ideology" simply did not exist for these men and was not related to use of violence. Instead, Smith piggybacked the attitude measure onto educational attainment and other "socioeconomic risk factors" and claimed he had "parsimoniously explained $20 \%$ of the variance in wife beating." Of course, it is impossible to tell what proportion of that is accounted for by projected attitudes since Smith offers no proof that people can accurately predict another's attitudes, let alone the precise contribution of the "attitudes" to the independent variable. Instead, Smith hypothesizes about a "violent subculture" made up of low income, violent men. You may ask, reading his paper, where is the violence?

Misleading research has tended to consistently err on the feminist side. For example, Reitzel-Jaffe and Wolfe (2001) examined history of family violence, negative beliefs, negative peer associations and current relationship abuse by male perpetrators. Using structural equation modeling, they examine history of exposure to family violence, "negative beliefs about gender roles," and "friends with these negative beliefs." The authors found that negative beliefs regarding gender and interpersonal violence were found to have a direct effect on relationship abuse. The study was done only on males (a form of "male chauvinist pig" theory) and did not consider that males with these subcultural beliefs may have girlfriends from within the same subculture. That aspect was never examined. Even though these young men were in university, they had non-normative beliefs and may have chosen like-minded girlfriends. The question that researchers focused on male violence never ask is this: why would a bright, independent young woman enter a relationship with these men? Were these women violent too? A study by Douglas and Straus (2003) showed women at the same university as this male sample were $167 \%$ as violent as males and a model of dating violence developed by Follingstad et al., that did include both partners behaviors found that both were significant predictors of couple abuse (Follingstad, Bradley, Helff, \& Laughlin, 2002). If the men in the ReitzelJaffe and Wolfe sample were violent, could not the "association" between male attitudes and violence both be byproducts of the female violence? Could this not also be true for unmeasured beliefs and attitudes in the females? Simon et al. (2001), in a methodologically sound study with a large and representative sample, found that only $2 \%$ of US men agree with the statement "it's ok for a man to slap his wife to keep her in line." Normative support for wife assault simply does not exist.

Results are routinely miscited in a direction favoring activist ideology, e.g., Arias, Dankwort, Douglas, Dutton and Stein (2002), DeKeseredy and Schwartz (1998), and Kimmel (2002). For example, Arias et al. (2002) describe how the "state of victimization among men is significantly lower" (p. 159). The authors state "Women were seven to fourteen times more likely to report that intimate partners had beaten them up, choked them, threatened or actually assaulted them with weapons, or attempted to drown them." The source they cite for these data is Stets and Straus (1992a,b, p. 156). However, Stets and Straus reported equivalent rates of violence by gender and were making the point that women were ten times as likely than men to report violence to the police (p. 155). Furthermore, Stets and Straus never reported the action by action data that Arias et al. report. This misstatement of results is so frequent in domestic violence research that Gelles and Straus (1988) invented a name for it: the "Woozle Effect" after an event in Winnie the Pooh where a mythological "Woozle" is discovered by its footprints (footprints made by the discoverers). Other Woozles include the following: DeKeseredy and Schwartz (1998) asked women who had been violent in a relationship since the age of 16 whether their own use of violence was in self-defense. Men were surveyed too $(n=1300)$ but were never asked questions about their own abuse victimization, only perpetration, guaranteeing a self-fulfilling prophecy. When both genders are asked about victimization and perpetration, college women are more violent than college men (Douglas \& Straus, 2003) across nineteen countries. 
Dekeseredy and Schwartz report levels of severity of violence used by women (according to their self-report) and the woman's own report of whether it was never, some, mostly or always self-defense. At both non-severe and severe levels of violence, these women (p. 82-83) report that their violence was rarely self-defensive; 422/678 and 205/356 in the non-severe and severe groups, respectively, reported that they "never" used violence in self-defense. Amazingly, the authors report "Our overall conclusion is that much of the violence by Canadian undergraduate women is selfdefense and should not be labeled mutual combat or male partner abuse" (p. 91).

It is hard to understand a methodological mistake this obvious. It is worth noting that other investigators (Follingstad et al., 2002) found that women reporting their motives for intimate partner violence listed control (not self-defense) as the most common motive.

Similarly, Kimmel's (2002) finding that "men who are assaulted by intimates are actually more likely to call the police, more likely to press charges and less likely to drop them" (p. 1345) needs examination. The claim, which is contradicted by large surveys, is based on three studies. One of these, Rouse, Breen and Howell (1988) was based on a small sample of 260 college students of whom males were slightly more likely to call police (4\% vs. $0 \%$ ) but also more likely to require medical help (5\% vs. 2\%). The second (Ferrante, Morgan, Indermaur, \& Harding, 1996), was based on a small sample in Australia. The third (Schwartz, 1987), was based on a reading of National Crime Survey data for a sample of 1743 . The focus of the study was on injuries (same for men and women) and the reference to calling police was as aside by the author but never reported in a data table. The representativeness of the sample is questionable, with $79.7 \%$ of the men reporting an injury. Kimmel does not report the data from the 1985 US National survey (Stets \& Straus, 1992a,b) that found, for a sample of $6000+$, that $8.5 \%$ of women and $.9 \%$ of men called the police. Hence, some selective referencing, and ignoring the larger and methodologically superior studies allowed Kimmel to come to this dubious conclusion. The conclusion is politically important to the feminist view as it supports the "crime victim surveys" that show gender asymmetry for intimate partner violence perpetration.

Despite Kimmel's claim that men call the police more frequently, they in fact, rarely do-(Brown, 2004; Laroche, 2005; Stets \& Straus, 1992a,b). Stets and Straus reported men calling police for less than $1 \%$ of assaults initiated by their partner (p.155). The reason for this is obvious. Men are rarely taken seriously by the police and charges are rarely laid (Brown, 2004; Buzawa, Austin, Bannon, \& Jackson, 1992). Brown found only moderate increases in police arrest of women, even when the man was injured. Buzawa et al. cite a case in Detroit where the police refused to arrest the woman despite the man's being stabbed in the back. Any studies that base estimates of domestic violence incidence on criminal justice statistics will be greatly biased. It is for this reason, we suspect, that Kimmel tries to manufacture the belief that men call the cops more often. The true finding reveals the bias in criminal justice studies.

Using techniques for assessing marital interaction that originated with Levenson and Gottman (1983) and assessed three dimensions of marital interaction, positive-negative affect, reciprocity and asymmetry, a University of Washington study focused marital interaction techniques on domestic violence. As used initially, Levenson and Gottman had only focused on marital satisfaction and had measured physiological linkage (interconnectedness in heart rate, skin conductance and pulse transmission time) using time series techniques for physiological measurement as well as self-report of affect using a video recall procedure. Their finding was that parallel patterning of physiological responses was related to reported marital satisfaction. In the UW studies these techniques would be used, on DV couples in an "experimental apartment" created in the psychology lab. Couples would re-create their most serious conflicts in that environment and physiological reactions would be measured.

In a high profile study of domestic violence, Gottman et al. (1995), Jacobson and Gottman (1998) and Jacobson, Gottman, Gortner, Berns and Shortt (1996) developed two fear-inducing names for male perpetrators: "cobras" and "pit bulls". The criterion for the grouping was wives' reports of husband violence on the CTS. Wives reports were used because "we assumed husbands might underreport their own violence" (Babcock, Waltz, Jacobson, \& Gottman, 1993, p. 42). The focus of the study was on husband violence and categories of violent husband derived from a popular book based on the research (Jacobson \& Gottman, 1998), classifying violent husbands as "pit bulls" (tenacious, emotional) or "cobras" (cool, instrumental). Couples were solicited as "couples experiencing conflict in their marriage." One has to read the fine print in the method section then to discover that "according to the wives themselves, almost half $(28 / 57)$ would have qualified for the DV group if wife violence had been the criterion" (Jacobson et al., 1994, p. 983). In other words, there were bilaterally violent couples in the mix, although the focus became entirely on the males. No measures were taken of the wives' use of violence and all independent variables focused on male violence as though it were being produced unilaterally in all relationships (even though it clearly was not). 
These are some of the consistent (in that they all support feminist views) misreporting errors that occur in domestic violence "research" and which contribute to the gender paradigm of male-perpetrator/woman-victim view. A fuller description is available in work by Dutton (2006) and Dutton and Nicholls (2005).

\section{Ripple effects of the patriarchal model}

\subsection{Criminal justice practice: does mandatory arrest reduce future assaults?}

Stemming from the ideological assumption that domestic violence is entirely a political act, mandatory arrest has been pursued as a necessary exercise of countervailing power, particularly necessary to overcome the putative patriarchal inclinations that may influence police discretion. The promotion of mandatory arrest for domestic accompanied a change in the common law rule authorizing police to make warrantless arrests in misdemeanor cases only when they observe the crime being committed. By 2000, all states authorized warrantless arrests of domestic violence offenders based solely on a probable cause determination that an offense occurred and that the person arrested committed the offense. In 21 states and the District of Columbia arrest is mandatory when the officer determines that probable cause exists (Miller, 2004).

What is the evidence that arrest is so effective in reducing domestic violence that the historical precedence of common law should be discarded and replaced not only with the permitting of arrest for unobserved misdemeanors, but the mandatory arrest for these particular unobserved misdemeanors?

Sherman et al. (1992) performed the largest and most extensive of six replications of the Sherman and Berk (1984) study. The arrest potential for recidivism reduction suggested by the Sherman and Berk study led to replications with larger samples in six US cities. Largest of the studies was in Milwaukee with 1200 cases of domestic violence. Sherman et al. (1992) addressed the question of whether arrest works to reduce recidivism for certain kinds of offenders and whether it may increase recidivism for others. Police responding to wife assault calls deemed the call eligible for the experiment if the victim was not seriously injured, the perpetrator was on the scene, and no warrants existed for his arrest.

Experimental treatments included "warning" (suspect not arrested but read warning of arrest if police have to return), "short arrest" (suspect arrested, booked, and released, typically within $2 \mathrm{~h}$ ) and "full arrest" (suspect arrested, booked, eligible for release on $\$ 250$ bail). These treatments were randomized within all eligible cases.

Outcome measures were subsequent "hotline" reports called in by all police to the local battered women's shelter whenever they encountered a case of wife assault (whether or not they could make an arrest). Arrests, offense reports, and victim interviews were also used as data. Using all of these data sources, the authors composed a "time at risk" index.

The initial effects of arrest were to suppress recidivism. For thirty days after the presenting incident, the prevalence (proportion of cases with one or more incidents) of repeat violence reported in the victim interviews was substantially lower in the arrest groups. However, at about 7-9 months after the presenting incident, the arrest and non-arrest recidivism curves cross over and from that point on the arrest group has a higher rate of recidivism. That is, for this sample, the long term effect of arrest was to increase the rate of repeat violence. This increase is small in magnitude but consistent across all measures of repeat violence. The arrested group averaged 124 days before repeating, whereas the warned group averaged 160 days. Hotline data showed a statistically significant long term escalation effect from arrest (but only for the short arrest group). The authors conclude that police departments with policies of releasing arrestees within $3 \mathrm{~h}$ of arrest might want to reconsider this policy.

The persons for whom arrest backfired in the long term were socially marginal (defined by the authors as black, unemployed, not married to the victim and high school dropouts). While arrest deterred those who were most likely to socially conform, it escalated other groups into higher frequencies of domestic violence. As Sherman et al. put it "When the majority of domestic violence incidents responded to by police involve unemployed suspects, then mandatory arrest fails to produce the greatest good for the greatest number" (p.160). Replications in Omaha and Colorado Springs confirmed these findings. In general, the authors conclude that in areas where urban problems are great and "marginality" high, arrest may be contraindicated. In other words, when general social constraints have broken down, arrest "in a vacuum" will not reduce recidivism in wife assault cases. Arrest only works for men with something to lose by being arrested.

There is another troubling aspect to the Milwaukee results. Mills (2003) reports the conclusion of Sherman et al. that when Milwaukee police arrest 10,000 Caucasian men, they produce 2504 fewer acts of domestic violence. When they arrest 10,000 African-American men, they produce 1803 more acts of domestic violence. If they have a pattern of 
arresting $3 \times$ as many black as white offenders (which is typical in many cities), they prevent 2504 acts of violence against white women at the cost of 5409 acts of violence against black women. If their results are generalizable, it would mean that mandatory arrest and release policies could endanger sub-groups of women in the long term, a point that the authors themselves raise. Garner and Maxwell (2000) make the point that the main contributor to the results in the Milwaukee experiment were the hotline calls and that this measure does not prove that an assault occurred but is merely a prima facie indication of an altercation. Hence, the shelter data does not prove deterrence from arrest.

The Omaha replication (Dunford, Huizinga, \& Elliott, 1990) found (and later studies confirmed) that when probable cause existed to make an arrest, the offender was absent $40 \%$ of the time and police did not wait to make an arrest. The use of arrest warrants was associated with less offending. Dunford et al. did not find a significant effect for arrest when the offender was present. The recidivism rate in Omaha was over $40 \%$ whereas it had been $26 \%$ in Minneapolis (despite a more restrictive measure of new violence in Omaha).

A subsequent replication in Charlotte, South Carolina also failed to find evidence for deterrence through arrest (Hirshell \& Hutchinson, 1992). Hirshell and Hutchinson (1992) added a feature of police-issued citations as a fourth treatment option. The investigators conclusion was that "arrest of spouse abusers is neither substantially nor statistically a more effective deterrent to repeat abuse than either of the other two responses (separation, mediation) examined in the study" (Garner \& Maxwell, 2000).

Two other replications were performed, in Dade County and in Colorado Springs. Both found a statistically significant effect of arrest when re-offending was measured through victim interviews but not when it was measured through police reports. The surveillance problem raised above may have occurred in Colorado: extensive interviewing of victims may have created a surveillance effect where the suppressed recidivism was created not by arrest per se, but by arrest + surveillance. The problem this raises is that such heightened surveillance in not possible under ordinary probation circumstances.

Garner, Fagan and Maxwell (1995) and Garner and Maxwell (2000) pooled data across all six replication sites to standardize the methodologies and measures. Using victim interviews (the more sensitive measure) as outcome measures, this re-analysis found that independent of site, length of time between initial and follow-up interviews, and suspect characteristics, offenders in the arrested group were significantly less likely to repeat their "aggression" (subsequent assaults, verbal threats of assault, and property damage) than those in the non-arrest group. Additionally, the frequency of re-offending was significantly lower in the arrest than the non-arrest group. However, no statistically significant effects of arrest were found when prevalence and frequency measures were based on officially recorded aggression. Even with victim interviews, estimated effect sizes were modest, especially compared to suspect characteristics, such as prior arrests and age, and a general trend of cessation over time held for both the arrested and nonarrested groups. In other words, individual characteristics counted more in generating cessation than did arrest and cessation occurred independent of arrest. Garner and Maxwell (2000) report the effect of arrest on future deterrence to be a change in subsequent aggression ranged from $4 \%$ to $30 \%$ depending on the data source and the measure of re-offending used. By comparison, the suspects' age and prior criminal history were associated with changes in subsequent reoffending of $50 \%$ to $330 \%$ (ten times as important). Across all sites, most suspects did not re-offend. Arrested suspects desist from further violence unless they are young and have a record of criminality. These offenders generated about five new incidents prior to follow-up interviews. As Sherman puts it "Does punishment deter crime? This question provokes fierce debates in criminology and public policy. Yet there is ample evidence that this is the wrong question. Widely varying results across a range of sanction studies suggest a far more useful question: under what conditions does each type of criminal sanction reduce, increase, or have no effect on future crimes?"(Sherman, 1993).

Sugarman and Boney-McCoy (1999) did a meta-analysis of all sites combined. They found, on average, no deterrence effect for arrest based on police data but a modest deterrence effect based on victim interview data. The only measure that could be used was frequency of new offending. As strange as it may seem, different data sets were collected at the various sites with little standardization. For a thorough discussion of these issues, the reader is directed to Garner and Maxwell (2000). Gelles (1996) argued that the media ignored subsequent studies that questioned deterrence effects.

The evidence in support of arrest for misdemeanor domestic violence is small and inconsistent. Arrest in some cases escalates violence. Mandatory arrest policies are a product of the ideologically driven view that since domestic violence is always strategic, always intentional, always unidirectional, and always with the objective of female domination by men that it must be contravened by the power of the state. Once one removes this ideological presumption, the rationale for mandatory arrest disappears. 


\subsubsection{Other legal sanctions}

Dugan (2003) re-analyzed data from the National Crime Victim Survey to ascertain whether legal sanctions in state statutes regarding domestic violence deter violence. These sanctions include: 1) beyond cohabitation — states that allow victims who do not live with offender to petition for a protection order, 2) custody - states that authorize the court to award temporary custody of children to the victim once a protection order is issued, 3) discretion index-range of sanctions available to a judge when a protection order is violated, 4) felony - states that classify protection order violations as a felony, 5) mandatory arrest - mandatory arrest laws for protection order violations and 6) states that confiscate offenders' firearms once a protection order is served. Note that these sanctions are for enforcement of protection orders, not assault.

Dugan then calculated odds ratios for these sanctions. The base rate for reporting any domestic violence incident was $0.5 \%$, ( 1 in 200 households) and spousal violence was $0.18 \%$. The custody sanction had a boomerang effect, increasing the odds of spousal assault by a factor of 1.2 (significant at .05 given the sample size). Mandatory arrest generated an odds ratio of .885 , a small effect, consistent with the Garner and Maxwell findings. No other state sanctions had significant effects on subsequent violence odds. The largest effect was for the status separated/divorced, an odds ratio of $4.3(p<.01)$ and clearly not a state legal sanction. In this study, the gender of the victim was not reported. Public housing had an odds ratio of .628. Dugan suggests that other apartment residents may serve as guardians to the victim.

One other issue remains for police/prosecutors who use mandatory arrest/no drop policies. Will the "overkill" nature of the response discourage women who want an end to a temporary conflict but do not want their husband arrested? Some data from Colorado suggest that they might: once mandatory arrest/no drop policy was instituted in Colorado Springs, in 1994; 911 calls for domestic violence began to decrease while other 911 calls increased with population increases. Dugan (2003) replicated this finding in her examination of post policy recidivism in the US. States that had brought in mandatory arrest, subsequently received only $85 \%$ as many $d v$ calls as those who had not.

Mandatory prosecution and "no-drop" prosecution policies were designed to shift the burden from the female victim to the state in intimate assault calls. However, they appear in many cases, to violate the wishes of the victim. In Colorado Springs, 911 calls for domestic disturbance declined after mandatory arrest was invoked (Dutton, 2006).

A study by Hotaling and Buzawa (2003) supports the Colorado finding. The authors examined the impact of case processing in the Quincy, Massachusetts (QDC) court on disclosure of re-victimization. The QDC was chosen as a data collection site because of its status as an acknowledged leader in implementing pro-intervention strategies in domestic violence cases and was a model program, recognized by VAWA (Violence Against Women Agency). Multivariate analysis was used to control for the impact of incident, victim, offender and case processing characteristics. Findings suggested the importance of indicators of victim frustration with the criminal justice system. Offenders of women who did not report were no more violent than those who re-reported. The decision to report revictimization was related to 1) a perception of the criminal justice system as unresponsive to their preferences (nonreporters said they had no voice or rights $55 \%$ of the time compared to $12 \%$ for reporters) and 2) being less likely to have wanted the offender prosecuted in the first place (Hotaling \& Buzawa, 2003). Offender dangerousness did not differ between groups. The authors conclude "what is troublesome is that this research has found that despite the victim's experience with a "model" intervention program, re-reporting was still a major concern as the majority of victims did not report subsequent offenses to the police. In fact, research adds credence to earlier expressed fears that a too aggressive criminal justice response that did not reflect diversity of victim desires might have had the unintended effect of deterring future reporting" (p. 28). The authors also suggest that because the majority of women chose to stay with the offender, the treatment that offenders were receiving needed to be improved. Overall these data tend to support the criticism of the criminal justice system response made by Mills (1999). As a reaction to the futility of many criminal justice practices, Mills (2003) has suggested restorative justice circles be used in an attempt to honor victims' wishes, which are frequently overlooked by criminal justice system reactions.

\subsection{Impact on custody assessment}

Domestic violence is very much as issue in custody assessments. In high conflict custody cases, interparental physical abuse rates run to 72-80\% (Johnston and Roseby, 1997; Newmark, Hartnell, \& Salem, 1995). Two recent 
publications (Bancroft, 2002; Jaffe, Lemon, \& Poisson, 2003) have linked domestic violence and custody assessment. Both are written with professional audiences in mind, both cite research studies on domestic violence with a view to expanding the awareness of "professionals, therapists, child protective and court personnel, battered mothers and to anyone else who is in a personal or professional position to touch the lives of children of battered women" (Bancroft \& Silverman, 2002, p. 13). Both provide one-sided analyses of domestic violence based on selfselected and non-representative samples. The relevance of these data for custody resides in the fact that, according to these authors, the co-occurrence of wife abuse and child abuse is high. Jaffe et al. (2003) put the co-occurrence of these types of abuse at $30-60 \%$. That is, "30-60\% of children whose mothers had experienced abuse were themselves likely to be abused" (p. 30). Jaffe et al. (2003) also note that direct abuse is not the only concern because the child becomes a pawn, used by the batterer to maintain abusive power and control in the relationship after separation. The authors then go on to define abuse using the "Duluth Power and Control Wheel" that includes "Using Male Privilege" (p. 40) as a part of an octant of abusive strategies used against women. Jaffe et al. (2003) then list three categories of "whom to assess": "victimized mothers" (p. 44), "battering fathers" (p. 46), and "war torn children" (p. 49). Jaffe et al. (2003) suggest using an abuse checklist given to the mother and asking the victimized woman to describe the "first, worst, and last" incident, followed by allowing the "alleged perpetrator an opportunity to respond." It is not clear what response, apart from denial, might be expected from an accused father. Indeed, the authors warn an assessor that the male perpetrator may "minimize their abusive behavior by blaming their victims or proclaiming that the abuse was uncharacteristic" (p. 42). It seems that, once accused, the father can only use responses that the evaluator is already primed to see as disingenuous. In addition, this view blinds assessors to another source of threat to children: their mother. As we will see below, severe physical child abuse is more likely to be perpetrated by mothers than fathers.

What is problematic about the analysis of Jaffe et al. (2003) is that while their description of the actions and consequences of abuse on the child is accurate, there is a priming of assessors to look only at the father as the abuse perpetrator, and having done so to suspect his denial of abuse. Denial of abuse will not exonerate him because highly abusive men deny abuse as well. Although Jaffe et al. (2003) tell evaluators to "review allegations with each party and give each side an opportunity to explain what happened" (p. 47) or to "have the alleged perpetrator complete a standard inventory about the abuse to engage him in a discussion about what transpired during the course of the relationship," they provide this suggestion to a reader who has already been informed that males are the perpetrators and that perpetrators lie. No algorithm is provided through which the truth might mystically emerge. Essentially the authors develop skepticism about male accounts and then advise the evaluator to use a clinical judgment already primed to disbelieve the alleged perpetrator. There is a substantial literature on the problems with clinical judgments (Grove \& Meehl, 1996; Kahneman, Slovic, \& Tversky, 1982), the essence of which is that actuarial judgments outperform clinical judgments consistently. Subjective "engaging in a discussion" with an evaluator, who is already primed to disbelieve the male respondent, is the very type of situation that forensic assessment has sought to eliminate.

Both Jaffe et al. (2003) and Bancroft and Silverman (2002) use "he" to refer to perpetrators of abuse and both are convinced that male abuse is by far the more serious. The section on battering fathers of Jaffe et al. (2003) has no counterpart called "battering mothers" (p. 46). These authors estimate the likelihood of mutual abuse in custody cases as only $9 \%$ (p. 54). Cases where the mother is the sole abuser are not considered or reported. Actual data from the U.S. National Survey, reported by Stets and Straus (1992a,b), showed that $28.6 \%$ of married couples were female violent (with a non-violent male) and 48.2\% used mutual physical abuse. In the 1975 US National survey, physical abuse by the mother was $10 \%$ more likely than physical abuse by the father (Straus, Gelles, \& Steinmetz, 1980).

Jaffe et al. (2003) devote one paragraph of their entire book to describing men as victims of female violence, pointing out that, in a study done by the Canadian Centre for Justice Statistics, rates of spousal victimization were only slightly higher for women than for men. This finding is quickly dismissed because the violence is "qualitatively different"; women reported more serious violence, three times as much physical injury, and more chronic violence.

Bancroft and Silverman (2002) express many of the same concerns about batterers as parents as do Jaffe et al. Both books have an awareness of the deleterious effects of a battering personality on vulnerable children, however, throughout both books, the terms "batterer" and "he" and "victim" and "mother" or "she" are used interchangeably. The eventual mindset is that abuse perpetrators are almost always male, and when they are not, the abuse is not serious. 
What Kahneman et al. (1982) call a "representative heuristic" is developed; batterers have the attributes of maleness and they alone pose a risk to the child.

Both books describe the developmental problems that occur in children of battered women. Indeed an entire literature has developed chronicling psychological problems of children from abusive families. This literature consistently assumes that the source of the abuse is the father. Almost without exception this literature is based on samples drawn from battered women shelters or from treatment groups for men who batter (Bancroft \& Silverman, 2002 , p. 13) and then inappropriately generalized to the general population.

For example, McCloskey, Figueredo and Koss (1995) describe their study as examining "the link between different forms of family aggression and children's symptoms of psychopathology" (p. 1239). They then recruited 365 women from women's shelters and the community. Even in the community sample, women "were screened for the presence of violence in the home in the year prior to the interview" (p. 1242). In other words, the entire sample was based on victimized women. Mothers and children were then asked to list abusive acts by both the mother and father. The authors stated that collecting samples of battered women from the community would "avoid bias in our sample" (sic). They also used a community control group that was "solicited without reference to family or partner violence" (p. 1242). Not surprisingly, in the battered women sample, children reported more violence from the fathers; the control sample children reported as much violence from their mothers as from their fathers. Mothers' reports of their own violence were not published. The McCloskey et al. literature review on effects of family violence on children focused exclusively on children of battered women and cited works by Jaffe amongst others. Hence, the domestic violence paradigm influences custody evaluators, again with misleading data either drawn from shelter samples and biased or misrepresenting the statistical risk of female violence in community samples.

Another example of the problem in applying the patriarchal paradigm based on shelter samples to the general public can be seen in a paper by Appel and Holden (1998). These authors found in a review of 31 studies that wife assault and physical abuse of children occurred from $20 \%$ to $100 \%$ when the sample selection basis was either battered women or abused children (average of 40\%). However, in "representative community samples," the overlap was only $6 \%$. In other words, the assumptions drawn from a shelter sample or a male perpetrator sample do not apply to community samples. Overlap rates diminish when items like "physically coerces" (as the authors point out, a legal form of punishment) were dropped from the study. The item "pushed, grabbed or shoved" generated the highest overlap, followed by "slapped and spanked." While these actions too are problematic, (Douglas \& Straus, 2003) they do not constitute "battering." They inflate overlap rates for apparent abuse; however, they do so by including corporal punishment of children in the equation even though this corporal punishment is not legally or technically abuse (so long as it does not injure the child as is done for correction). As the authors put it, "some of the highest rates of overlap came from reports of children of battered women but these reports included slap/spank" (p. 585). Even after examining the data on co-occurrence and noting that all came from women's reports and that shelter samples were not representative of community samples, Appel and Holden (1998) outline five models of cooccurring spouse and physical child abuse. Not one of these models depicts the wife as a sole perpetrator of abuse to the husband. This argument creates an erroneous impression that spouse assault is entirely husband to wife and that such assault has a high likelihood of being accompanied by physical child abuse.

Just to set the record straight, a large sample survey of child abuse allegations was done by the Canadian government (Trocme, 2001), examining 135,573 child abuse investigations. About 45\% of these were substantiated (no difference in substantiation rates by gender). Mothers were more likely than fathers to be perpetrators for physical abuse, emotional maltreatment and neglect (p. 49).

\subsection{Beliefs about gender and violence perpetration}

Emphasis on male violence has been promulgated as well with police departments to the point where males are disproportionately arrested for equivalent violence as females (Brown, 2004). In a random digit dialed survey of 3679 residents of Los Angeles, Sorenson and Taylor (2005) found that actions are considered abusive by the general public if performed by males. This was true across all sociodemographic groups. This includes what we normally would call "psychological abuse", not just physical abuse. Furthermore, respondents deemed the same action when performed by a man (as "should be illegal"). This included "punch" and "pressure for sex".

Of perhaps greater concern to psychologists is that Follingstad, DeHart and Green (2004) found that this gender bias was also true of psychologists. Two scenarios describing the context and psychologically abusive behaviors with the 
genders reversed were given to 449 clinicians (56\% male), median age 52. Psychologists rated male perpetrated behavior as more abusive and severe than the wife's use of the same actions. Contextual factors (frequency/intent/ perception of recipient) did not affect this tendency. The items rated as significantly more abusive if performed by a man included "made to account for whereabouts at all times," "would not allow to look at members of same sex," "threatened to have committed to an institution" and "made derogatory comments." The significance on these items was independent of the sex of the psychologist.

As Follingstad et al. concluded, "the stereotypical association between physical aggression and males appears to extend to an association of psychological abuse and males" (p. 447). Unfortunately this sometimes leads to serious problems. Coontz, Lidz and Mulvey (1994) found that clinical predictions of dangerousness made in psychiatric emergency rooms consistently underestimated female dangerousness. Predictions that a male would not be violent were correct $70 \%$ of the time, but for females, they were correct only 55\% of the time. Skeem et al. (2005) had 147 clinicians assess 680 patients in a psychiatric emergency room for risk of future violence. Mental health professionals of both genders were "particularly limited in their ability to assess female patients" risk of future violence" (p. 173). In fact the "false negative rate" for female patients (the rate at which one was judged to be low risk but subsequently reoffended) was double that of male patients (p. 181). The criterion for violence was physical violence: the patient had to have been reported to have "laid hands on another person with the intent to harm him or her, or had threatened someone with a weapon in hand" (p. 178). This finding was true across all professional groups and was unrelated to type of violence. That is, the finding occurred for general violence and for severe violence. In the MacArthur Risk Assessment study of psychiatric patients released into the public, Robins et al. (1987) found that women were just as likely as men to be violent during the first year after discharge. Robins and her colleagues attributed the underestimation of women's violence to it being less visible "since it occurs disproportionately in the home with family members" (p. 182). An urban emergency room in Pennsylvania (Mechem, Shofer, Reinhard, Hornig, \& Datner, 1999) that asked about sources of male injuries, found that $13 \%$ of 866 male patients were injured by their female intimate partner.

\section{Moving beyond gender analysis}

\subsection{Meta-analysis of gender differences in aggression}

The most comprehensive study on gender differences in intimate violence was conducted by Archer (2000). This meta-analytic study examined combined results from 82 independent studies (including the National Violence Against Women Survey) where data were available for comparing gender rates of abuse perpetration. Based on combined data across studies (a combined data sample of 64,487), women were slightly more likely than men to use physical abuse (defined using the CTS) against an intimate partner (effect size or $d^{\prime}=-.05$ ). This was true whether or not outliers were removed or whether studies with a ceiling $n$ of 800 were considered to offset swamping of the outcome by studies with huge samples. Samples from shelters were unrepresentative of community samples, since, by definition they were male violent-female victim samples. This was not true of community samples. As with the dating samples reported above, the younger the sample, and the higher the level of female violence relative to male violence.

Medical treatment for injuries across studies revealed an effect size of +.08 , with women being slightly more likely than men to seek treatment (Archer, 2000). Neither the use of violence nor medical treatment resulted in a large effect size. An effect size of $d^{\prime}=.08$ is less than $1 / 10$ of a standard deviation difference between genders. Given the methodology employed by Archer, his work has to be considered the "gold standard" of studies in gender usage of violence.

In addition, large sample longitudinal studies (to be reviewed below) have shown that personality disorder and substance abuse, not gender, are the key predictive factors (Ehrensaft, Cohen, \& Johnson, in press; Ehrensaft et al., 2004; Moffitt et al., 2001). Furthermore, evidence speaks strongly against any normative acceptance of wife assault. Data from a large, nationally representative sample of 5238 adults in the US found that acceptance of male to female violence was low in all sub-samples, regardless of gender or ethnicity (Simon et al., 2001). Overall about only $9.8 \%$ of males (and 7.2\% of females) approved of a man hitting a woman even "if she hits him first." Only $2.1 \%$ of men (and $1.4 \%$ of females) approved of a man hitting a woman "to keep her in line." Hence, the "norm of acceptance" of violence towards women upon which patriarchal theory is based (Dobash \& Dobash, 1979), is a myth. Evidence also contradicts the simplistic patriarchal view of male power in marriage; only $9.6 \%$ of marriages report they are "male dominant" (Coleman \& Straus, 1992). 


\subsection{Longitudinal peer cohort studies and the reconceptualizing of female intimate partner violence}

A number of longitudinal peer cohort studies have now been concluded. These studies have several methodological advantages over prior "snapshot" studies in that they all use large and demographically representative samples and follow these samples over extended time periods. Hence, the etiology of abusive behaviors can be traced prospectively. This set of studies, focusing specifically on developmental trajectories of female aggression has been ignored by the domestic violence paradigm. A recent collection of several such studies has been published (Putallaz \& Bierman, 2004) incorporating thirteen independent studies of female aggression. The collection examines the development of both traditional forms of female aggression (indirect) and more direct (against children and intimates). One of these studies, Serbin et al. (2004) reports on the Concordia Longitudinal Risk Project in Montreal, a study that began in 1976 with a sample of 4109 . Children were categorized into aggressive and withdrawn categories using the Pupil Evaluation Inventory. Extremes in aggression were developed by taking children who scored above the 95th percentile on aggression and below the 75th on withdrawn. This subsample yielded 101 girls and 97 boys (similarly reverse criteria yielded a "Withdrawn" group of 129 girls and 108 boys). Age matched comparisons were developed by taking children who were between the 25th and 75th percentile (average) on both aggression and withdrawal. Serbin et al. describe their sample as "community based "and therefore "avoiding biases inherent in clinic-referred samples" ( $p$ 266). Aggressive children of both sexes had lower IQs and academic achievement than comparison controls. Both were more physically aggressive during play. Girls' aggression was associated with a preference for male partners who were also aggressive. As they approached adolescence, these aggressive girls had elevated rates of smoking, alcohol and illicit drug use and "continue (d) to seek out behaviorally compatible peer groups, probably comprised of boys and girls with similar aggressive or "predelinquent" behavioral styles" (p. 268). They also had elevated rates of gynecological problems and were more likely to go on birth control sooner. They had elevations in rates of sexually transmitted diseases between ages 14 and 20. The aggressive group had elevated levels of depression and anxiety disorder by late teens. When they married their children had higher health and the "Aggressive" girls had become aggressive mothers, exhibiting maternal childhood aggression and having children who had more visits to the ER, specifically for treatment of injuries.

Magdol et al. (1997) followed a birth cohort of 1037 subjects in Dunedin, New Zealand. As they put it, "Early studies of partner violence assumed that men's perpetration rates exceeded those of women, in part because these studies relied almost exclusively on clinical samples of women who sought assistance or of men in court-mandated counselling programs" (p. 69). At age 21, 425 women and 436 men who were in intimate relationships from the Magdol et al. cohort answered CTS questions about their own violence and their partners' use of violence. Both minor and severe physical violence rates were again higher for women whether self- or partner-reported. The female severe physical violence rate was more than triple that of males (18.6\% vs. 5.7\%). Stranger violence was also measured and was again more prevalent by women than men ( $36 \%$ vs. $25 \%)$.

In a further report on the Dunedin sample, Moffitt et al. (2001), reported that antisocial traits in females 1) made them more likely to become involved in a relationship with an abusive man and 2) even after controlling for their partners physical abuse, "women with a juvenile history of conduct problems were still more likely to commit violence against their partners" (op. cit., p. 65). With a longitudinal study earlier data can be used to forecast later behavior. Antisocial behavior in women measured at age 15 was predictive of assaultive behavior towards intimate partners at age 21. This sample was originally selected when they were quite young and was demographically representative of persons their age. A similar design was used in the US and found the same results with respect to gender parity of violence (Morse, 1995).

Capaldi, Kim and Shortt (2004) examined data from an ongoing community-based longitudinal study of youth in Oregon (Oregon Youth Study: OYS). By young adulthood, 9\% of men and 13\% of women were identified as engaging in frequent partner violence. Consistent with prior findings, frequent violence was most common in relationships with bidirectional abuse. As far as injuries were concerned, $13 \%$ of the young men and $9 \%$ of the women indicated they had been hurt at least once by partner violence, and again injury was also likely to be mutual. No gender differences were found in fear of partner's abusive behavior. Women's prior antisocial behavior and depressive symptoms predicted both their own abusive partner behavior, as well as their male partners' abuse. Notably, the women's characteristics were predictive over and above the contribution of their male partners' antisocial characteristics. These findings suggest assortative mating for antisocial behavior, as well as the independent contribution of women's risk factors to 
the development of violent relationships. Stability of aggression was found for both genders. As Capaldi et al. concluded "aggression thus appears to be predominantly bidirectional" (p.235).

Ehrensaft et al. (2004) reported that, in the Dunedin birth cohort of 980 individuals, $9 \%$ were in "clinically abusive relationships", defined as those that required intervention by any professional (e.g., hospital, police, lawyers). More such help exists for women, and they are more likely to use it (Stets \& Straus, 1992a,b), so the results may be skewed. However, the authors found comparable rates of violence, $68 \%$ of women and $60 \%$ of men self-reporting injury. Both male and female perpetrators evidenced signs of personality disturbance. The authors noted, for instance, the women had "aggressive personalities and/or adolescent conduct disorder" (p. 267). As the authors put it, "these findings counter the assumption that if clinical abuse was ascertained in epidemiological samples, it would be primarily man-towoman, explained by patriarchy rather than psychopathology" (p. 258).

The Montreal, Oregon and Dunedin studies present clear examinations of the development and expression of aggression to others in a female sample. They show the developmental trajectory and the "trait" character of this aggression. Both studies indicate that these women will select aggressive men and contribute to the intra-couple aggression.

Ehrensaft et al. (in press) followed an unselected sample of 543 children over 20 years to test the effects of parenting, exposure to domestic violence between parents (ETDV), maltreatment, adolescent disruptive behavior disorders and substance abuse disorders on risk of violence to and from an adult intimate partner. Conduct Disorder (CD) was the strongest predictor of perpetration for both sexes, followed by ETDV. Essentially, the CD in some individuals developed into a variety of adult personality disorders. Ehrensaft et al. call these personality disorder trajectories. A failure of personality disorders to decline predicted intimate violence in both sexes. Women with a pattern of distrust, interpersonal avoidance, unusual beliefs and constricted affect were more likely to assault intimate male partners. Personality disorder, not gender, predicted violence. As the authors put it "it was personality functioning measured prospectively from adolescence to early adulthood (that) can distinguish individuals who will go on to perpetrate partner violence".

Pimlott-Kubiak and Cortina (2003) analyzed the US National Survey of Violence Against Women (Tjaden \& Thoennes, 1998) study of gender differences in incidence of abuse and traumatic reactions to intimate violence, stalking and emotional abuse. The authors cluster analyzed the reports from the NVAWS, identifying 8 distinct profiles of exposure profile to various forms of abuse. Of the 16,000 respondents, men were more likely than women to report exposure to physical abuse (albeit outside the home more than inside), women more likely to report exposure to sexual abuse. Of the 8000 women interviewed about 390 had experienced "multiple forms of abuse" as an adult, as had 350 men. The authors examined a variety of adverse reactions to abuse victimization (depression, PTSD, alcohol abuse) and found no difference by gender. The main predictor of adverse reactions was frequency of exposure, not gender. No meaningful interactive effects of gender and interpersonal aggression were found, once lifetime exposure to aggressive events was adequately taken into account. The authors concluded that their findings argued against theories of greater female vulnerability to pathological outcomes.

Some have argued that female violence is not "instrumental and controlling" as is male violence (Johnson, 1995). However, Laroche (2005) re-analyzed data from the General Social Survey of 25,876 persons in Canada. Unlike Johnson's data, this survey asked men about their wives' control tactics. Hence, female "intimate terrorists" emerged from the data, something that Johnson had never described. Laroche clearly found that female intimate terrorists existed (women who used violence and control tactics), at a rate of $2.6 \%$ compared to $4.2 \%$ for male intimate terrorists. Laroche found that men who were terrorized by female intimate terrorists were as afraid as women terrorized by males ( $83 \%$ vs. $77 \%$ of women). This was verified using as assessment of controlling behaviors developed by Johnson and Leone (2005) and used in the Canadian General Social Survey. There appears to be no difference by instrumentality between genders and again, no difference in reported fear of violence.

\subsubsection{Consequences of underestimating of female violence}

The underestimation of female violence occurs in police departments to the point where males are disproportionately arrested for equivalent violence as females.

The most common form of intimate partner violence is bilateral (Stets \& Straus, 1992a,b). That being the case, studies of couple interaction that result in violence are important and several have been done (Jacobson et al., 1994; Leonard \& Roberts, 1998; Margolin et al., 1989). These studies have found escalating negative reciprocity to precede assaultive behavior, suggesting that couples therapy may be required in many cases of intimate partner violence. Some 
positive results of such work have been reported (O’Leary, Heyman, \& Neidig, 1999; Stith, Rosen, \& McCollum, 2003) but couples work is mandated as unacceptable by activists even though an assessment could determine whether the couple might benefit from couples work (e.g., where violence was bilateral and there was no current risk). This is another example of the monolithic view of current practice. Acknowledging the interactive nature of much IPV would allow marriage and family therapist to operate instead of Duluth interventions.

\subsection{The connection between anger and violence}

One shibboleth of the Duluth philosophy (Pence \& Paymar, 1993) is that anger does not cause violence (p. 9, 105). The Duluth perspective is rather critical of cognitive-behavioral treatment (CBT) which it frequently mislabels as "anger management," although CBT has never focused primarily on anger and anger management would be one of approximately 16 treatment objectives in CBT. Duluth's view of abuse is that it is always an instrumental, strategic act and hence, not a product of anger. Again, this view is not supported by the evidence that Maiuro, Cahn, Vitaliano, Wagner and Zegree (1988) found that domestically violent men had significantly higher levels of both anger and hostility than controls. The author concluded that their findings supported the "idea that anger dyscontrol is a key issue in the profile of domestically violent men" (p.17) and noted that depression, as well as anger was elevated in this group. Margolin et al. (1989) found that physically aggressive husbands reported significantly higher levels of anger than husbands in three control groups. Dutton and Browning (1988) showed videotaped husband-wife conflicts to wife assaulters and control males. The assaultive males reported significantly higher levels of anger, especially in response to an "abandonment" scenario than controls. Dutton and Sonkin's (2003) application of attachment theory to intimate violence (see below) also contradicts this notion. According to attachment theory, insecure attachment patterns are essentially maladaptive methods of regulating affect, particularly anger and other emotions stemming from loss.

Dutton and Starzomski (1994) found elevated anger scores for assaultive men as measured by the Multidimentional Anger Inventory(Siegel, 1986). They related the anger to certain personality disturbances, especially Borderline Personality Disorder, Antisocial PD, Aggressive-Sadistic PD and Passive-Aggressive PD, all of which have anger as a component of the personality disorder. Dutton et al. (1994) found elevated anger in assaultive males to be related to certain attachment disorders, especially an attachment style called "fearful" attachment and which they re-labeled "fearful-angry" attachment. Citing Bowlby's (1977) work on attachment that viewed anger as having a first function of re-uniting with an attachment object and dysfunctional anger as further distancing the object. Dutton et al. (1994) explored developmental origins of elevated anger in assaultive males, viewing it as being produced by paternal rejection, exposure to abuse and a failure of protective attachment. Failure to address these underlying issues therapeutically while focusing on symptomatic beliefs and "male privilege" would be counter-indicative of treatment success.

Jacobson et al. (1994) recruited physically aggressive and martially distressed non-violent control couples to discuss "areas of disagreement" in a laboratory setting. Both martially violent husbands and wives displayed significantly more anger than controls (although the study focused on, and reported abusive husbands, $50 \%$ of the wives committed severe acts of abuse as well (p.983)).

Eckhardt et al. (1998) and Eckhardt, Barbour and Stuart (1997) reviewed several anger measures and argued that anger and hostility were both elevated in martially violent men. Eckhardt et al. (1998) used an "articulated thoughts simulated situations" technique that found martially violent men articulated more anger-inducing irrational thoughts and cognitive biases than non-violent controls. In short, numerous studies from several independent sources have found anger to be prominent in physically assaultive males. For a review of studies not reported above, see Eckhardt et al. (1997).

\subsection{Patriarchal beliefs and violence}

A central tenet of the Duluth model is that male intimate violence is a product of "patriarchal beliefs". However, the evidence that patriarchal beliefs cause violence has very little empirical support. A recent meta-analytic review by Stith, Smith, Penn, Ward and Tritt (2004) found only modest effects for "traditional sex role ideology" on partner violence. Stith et al. required four independent studies to show an effect before a factor could be considered a risk factor for intimate partner violence. However, two of the four studies they cited for attitudinal acceptance had dubious measures 
of attitude (one took reports of females on their husbands attitudes) (Smith, 1990), the other simply asked abusive and non-abusive men to estimate the likelihood of their being violent in the future and took elevated (and probably accurate) estimates of violent men as measures of "acceptance" (Hanson et al., 1997). The result is that evidence for an association between attitudes and IPV is meager and even if it existed, the causal direction cannot be ascertained by cross-sectional studies.

Measures of beliefs taken post hoc may simply reflect rationalizations for previous violence and causation cannot be inferred. Social psychological research perennially demonstrates that people adjust their attitudes to reconcile attitudes with behavior (Bem, 1972). Also, beliefs and irrational thoughts increase during arousal to anger and, despite the Duluth denial that anger is important, it is typically a prior state aspect of abusive episodes. What the Duluth proponents fail to acknowledge, is that thoughts, emotions and behaviors are inter-related, but that this interaction is bidirectional. For example, when under the influence of strong emotions, thoughts or beliefs may become distorted which in turn will lead to particular behaviors. Likewise, pre-existing thoughts or beliefs may also exacerbate emotions (such as, I cannot depend on anyone for love) also leading to problematic behaviors. Likewise, behaviors can trigger thoughts or emotions that were not present before the action was taken. For example, one can smile and shortly afterwards begin to feel happy. Additionally, many behaviors can occur in a mindless way, with little awareness to thought or emotion (riding a bike for example). In other words, the Duluth model of thoughts and behaviors is simplistic and fails to capture the true complexity of the human intimate relationship. Perhaps this is the central tragedy of the beliefs underlying the Duluth model: that men and women are reduced to socially scripted automatons, without painful personal histories, without current frustrations, and inevitably without meaningful inner lives.

\section{Conclusion}

It is unfortunate that a once pioneering model has become an impediment to effective program and criminal justice responses to domestic violence. What was intended to be a progressive force for safety and liberation has become a rationale for narrow-minded social control. The Duluth model, and its underlying ideological assumptions, is incompatible with progressive social theory and policy. Progressive views of crime and deviance identify, in part, risk factors rooted in socioeconomic marginalization. These broad indicators of socioeconomic risk are often found to be associated with violence and criminality (Markowitz, 2003) The Duluth model, however, maintains that unlike the bulk of similar aggressive criminal behaviors (e.g., assault, child abuse, elder abuse), violence perpetrated toward women is influenced in no way by social marginalization or psychosocial deficits, but rather is solely a product of gender privilege. A progressive view makes possible a reduction in crime and violence through ameliorating socioeconomic disadvantage. The Duluth model renders such efforts irrelevant.

This is a period of great political polarization. Liberal and conservative perspectives on most social issues have become extreme in their divergence. It is an error to pigeonhole this critique of the Duluth model as a "left-right" issue. It is not. It is a critique of ideologically driven suppression of science, rational policy models, and innovative, promising program development. Scientific empiricism is often rejected by both the left and the right when findings deviate from approved ideological or theological views. The "strange bedfellows" consensus about always-guilty, brute, male perpetrators and always-innocent, pure, female victims speaks to a deeper set of cultural archetypes underlying the shared prejudice of both the left and right on this issue. What is the appeal to "conservatives" of what appears to be a "liberal feminist" framing of this issue, with its use of activist rhetoric? Simply put, it provides a rationale for the further criminalizing of deviance and an expansion of the power of the criminal justice system. For example, the federal STOP Violence Against Women Formula Grant Program makes ineligible for funding "intervention or counseling programs for perpetrators that do not use the coercive power of the criminal justice system to hold them accountable for their behavior" (italics added) (Programs, 2004-2005).

There is a closed-mindedness shared by the left ("feminist") and right ("law and order") perspectives on the issue of domestic violence. Both views share a belief that the exercise of social control is the preferred response. Both share a commitment to the belief that criminal behavior ("battering") is fully voluntary and strategic, independent of psychological or psychiatric mediation. This dismal coupling of the progressive and repressive is not uncommon in social policy. Corvo and Johnson (2003) identified a "historical precedent for such sociopolitical sleight of hand, for the substitution of regressive social control measures for progressive policy in 
the guise of social enlightenment, particularly where the welfare of women and children is putatively concerned" (p. 265). Corvo and Johnson describe the views underlying the Duluth model not as feminism per se, but as a form of fundamentalism. The meaning here in its psychological not theological sense, connoting an "us against them" ideology and a conviction of the infallibility of one's beliefs despite contradiction of these claims by empirical reality. This mindset is often reflected by the labeling of any dissent as "backlash," never as a well founded methodological critique (DeKeseredy \& Schwartz, 2003; Faludi, 1981). Duluth model adherents are interfering with the delivery of effective treatment intervention through state laws or policy that require a genderbased but ineffective "intervention" as the model of choice. This disadvantages women partnered with men in treatment by precluding the availability of more effective psychologically based treatment. As Ehrensaft et al. (2004) put it "studies suggest that this single-sex approach is not empirically supported, because both partners' behaviors contribute to the risk of clinically significant partner abuse, and both partners should be treated. Women's partner abuse cannot be explained exclusively as self-defense against men's partner abuse, because a woman's pre-relationship history of aggression towards others predicts her abuse toward her partner, over and above controls for reports of his abuse towards her" (p. 268).

We call upon the federal agencies with responsibilities for addressing issues of violence and domestic violence to initiate funding programs designed to encourage innovative perpetrator intervention programs. We call upon the state and local offices responsible for maintaining standards for perpetrator intervention to not only permit, but to encourage local shelters and other providers to develop and implement effective programs. We call upon those who study domestic violence to maintain high standards of scientific and methodological rigor regardless of ideological critique. We call upon those involved in helping these troubled persons and families to apply the sound principles of humane, effective practice that their various professions promote. Against a national movement toward evidencebased and best-practice criteria for assessing program continuance, interventions with perpetrators of domestic violence remain immune to those evaluative criteria. The stranglehold on theory and policy development that the Duluth model exerts confounds efforts to improve treatment. There is no rational reason for domestic violence to be viewed outside of the broad theoretical and professional frameworks used to analyze and respond to most contemporary behavioral and psychological problems. On the contrary, this isolation of domestic violence has resulted in a backwater of tautological pseudo-theory and failed intervention programs. No other area of established social welfare, criminal justice, public health, or behavioral intervention has such weak evidence in support of mandated practice.

The bureaucrat/activists of certifying agencies and "batterer" treatment programs have become "true believers," disregarding research that does not support their views (Dutton \& Nicholls, 2005). They are enthralled with the power that comes with having one's philosophy hold sway and the control they feel from influencing criminal justice policy. Ironically, they often attribute these very "power and control" motives to abusive men. There is no other explanation for resisting treatment that would disprove their philosophy but make the lives of women safer. Is time to relinquish this hegemony of policy and allow the treatment of abusive men, women, and families by professionals who can make clear judgments about appropriate treatment (e.g., couples therapy, family therapy, and group therapy for one or both of the couples' members) and end the current dysfunction in criminal justice process. Treatment modalities exist that show great promise but are not tried for political reasons. Psychologists, social workers, and other helping professionals have not only a broader array of research-based behavioral change technologies available to them, but also a commitment to rigorous codes of ethics. These codes of ethics may vary in the details, but all leave no doubt as to the primacy of human dignity, growth, and safety. Further, these codes of ethics promote dynamic, scientific views of practice excluded from the approved interventions promulgated by the state certifying agencies (APA, 2002; Howard, McMillen, \& Pollio, 2003).

Those with continued allegiance to the patriarchal view should stand back and ask themselves if their primary motivation is to advance the safety of women and families or to preserve a self-interested political stance. The patriarchal view played an important role in addressing domestic violence. If not for the early groundbreaking work of victims' rights advocates and feminist activists, it is not likely that domestic violence would be so recognized as an important social welfare and public health issue. In the evolution of public policy responses to social problems, the path often followed is an initial politicizing of the issue, followed by programs, followed by evaluations research, followed by a more detailed specification of etiology, risk, and program response. This process has been impeded by the ideological strictures inherent in the patriarchal view. The science has moved well beyond the policy. It is time for the policy to change. 


\section{References}

APA. (2002). Code of Ethics. from http://www.apa.org/ethics/code2022.html

Appel, A. E., \& Holden, G. W. (1998). The co-occurrence of spouse abuse and physical child abuse: A review and appraisal. Journal of Family Psychology, 12(4), 578-599.

Archer, J. (2000). Sex differences in aggression between heterosexual partners: A meta-analytic review. Psychological Bulletin, 126(5), 651-680.

Archer, J. (2005). Cross-cultural differences in physical aggression between partners: A social-structural analysis.

Arias, I., Dankwort, J., Douglas, U., Dutton, M. A., \& Stein, K. (2002). Violence against women: The state of batterer prevention programs. Journal of Law, Medicine and Ethics, 30, 157-165. American Society of Law, Medicine and Ethics.

Babcock, J. C., Green, C. E., \& Robie, C. (2004). Does batterers' treatment work?: A meta-analytic review of domestic violence treatment outcome research. Clinical Psychology Review, 23, 1023-1053.

Babcock, J. C., Waltz, J., Jacobson, N. S., \& Gottman, J. M. (1993). Power and violence: The relation between communication patterns, power discrepancies, and domestic violence. Journal of Consulting and Clinical Psychology, 61(1), 40-50.

Bancroft, L. S., \& Silverman, J. G. (2002). The batterer as parent: Addressing the impact of domestic violence on family dynamics. Thousand Oaks, CA: Sage.

Bem, D. J. (1972). Self-perception: An alternative interpretation to cognitive dissonance phenomena. Psychological Review, 74, $183-200$.

Bograd, M. (1988). Feminist perspectives on wife abuse: An introduction. In M. Bograd, \& K. Yllo (Eds.), Feminist perspectives on wife abuse (pp. 11-26). Beverly Hills: Sage.

Bowlby, J. (1977). The making and breaking of affectional bonds. British Journal of Psychiatry, 130, 201-210.

Brown, G. A. (2004). Gender as a factor in the response of the law-enforcement system to violence against partners. Sexuality and Culture, 8(3-4), $1-139$.

Buttell, F. P., \& Carney, M. M. (2002). Psychological and demographic predictors of attrition among batterers court ordered into treatment. Social Work Research, 26(1), 31-42.

Buzawa, E. S., Austin, T. L., Bannon, J., \& Jackson, J. (1992). Role of victim preference in determining police response to victims of domestic violence. In E. S. Buzawa, \& C. G. Buzawa (Eds.), Domestic violence: The changing criminal justice response Westport, Conn: Auburn House.

Capaldi, D. M., Kim, H. K., \& Shortt, J. W. (2004). Women's involvement in aggression in young adult romantic relationships. In M. Putallaz, \& K. L. Bierman (Eds.), Aggression, antisocial behavior, and violence among girls New York: Guilford.

Coleman, D.H., and Straus, M.A. (1985). Marital power, conflict, and violence. Paper presented at the The meeting of the American Society Criminology, San Diego, CA.

Coleman, D. H., \& Straus, M. A. (1992). Marital power, conflict and violence in a nationally representative sample of American couples. In M. A. Straus, \& R. J. Gelles (Eds.), Physical violence in American families (pp. 287-300). New Brunswick: Transaction.

Coontz, P. D., Lidz, C. W., \& Mulvey, E. P. (1994). Gender and the assessment of dangerousness in the psychiatric emergency room. International Journal of Law and Psychiatry, 17(4), 369-376.

Corvo, K., \& Johnson, P. J. (2003). Vilification of the "batterer": How blame shapes domestic violence policy and interventions. Aggression and Violent Behavior, 8(3), 259-281.

Davis, R. C., Taylor, B. G., \& Maxwell, C. D. (1998). Does batterer treatment reduce violence? A randomized experiment in Brooklyn. Justice Quarterly, 18, 171-201.

Davis, R. C., Taylor, B. G., \& Maxwell, C. D. (2000). Does batterer treatment reduce violence? A randomized experiment in Brooklyn. Washington, DC: National Institute of Justice.

DeKeseredy, W. S., \& Schwartz, M. D. (1998). Woman abuse on campus: Results from the Canadian National Survey. Thousand Oaks: Sage.

DeKeseredy, W. S., \& Schwartz, M. D. (2003). Backlash and whiplash: A critique of Canada's general social science survey on victimization. Online Journal of Justice Studies, 1(1).

Dobash, R. E., \& Dobash, R. P. (1979). Violence against wives: A case against the patriarchy. New York: Free Press.

Dobash, R. P., Dobash, R. E., Wilson, M., \& Daly, M. (1992). The myth of sexual symmetry in marital violence. Social Problems, 39(1), 71-90.

Douglas, E. M., \& Straus, M. A. (2003 August). Corporal punishment experienced by university students in 17 countries and it's relation to assault and injury of dating partners. Paper presented at the European Society of Criminology, Helsinki, Finland.

Dubin, R. (1978). Theory building. New York: Free Press.

Dugan, L. (2003). Domestic violence legislation: Exploring its impact on the likelihood of domestic violence, police intervention and arrest. Criminology and Public Policy, 2, 283-312.

Dunford, F. W. (2000). The San Diego navy experiment: An assessment of interventions for men who assault their wives. Journal of Consulting and Clinical Psychology, 68(3), 468-476.

Dunford, F. W., Huizinga, D., \& Elliott, D. S. (1990). The role of arrest in domestic assault. The Omaha police experiment. Criminology, 28(2), 183-206.

Dutton, D. G. (1985). An ecologically nested theory of male violence toward intimates. International Journal of Women's Studies, 8(4), 404-413.

Dutton, D. G. (1994). Patriarchy and wife assault: The ecological fallacy. Violence and Victims, 9(2), 125-140.

Dutton, D. G. (2000). Witnessing parental violence as a traumatic experience shaping the abusive personality. Journal of Aggression, Maltreatment and Trauma, 3(1), 59-67.

Dutton, D. G. (2001). The neurobiology of abandonment homicide. Aggression and Violent Behavior, 7, 1-15.

Dutton, D. G. (2002). The abusive personality: Violence and control in intimate relationships. New York: Guilford Press. Revised Paperback Edition.

Dutton, D. G. (2003). Treatment of assaultiveness. In D. G. Dutton, \& D. L. Sonkin (Eds.), Intimate violence: Contemporary treatment approaches. New York: Haworth Press. 
Dutton, D. G. (2006). Rethinking domestic violence. Vancouver B.C: UBC Press.

Dutton, D. G. (in press). Personality profile of intimate terrorists. Journal of Interpersonal Violence.

Dutton, D. G., \& Browning, J. J. (1988). Power struggles and intimacy anxieties as causative factors of violence in intimate relationships. In G. Russell (Ed.), Violence in intimate relationships. Great Neck, New York: PMA Publishing.

Dutton, D. G., \& Holtzworth-Munroe, A. (1997a). The role of early trauma in males who assault their wives. In D. Cicceti, \& R. Toth (Eds.), The rochester symposium on development. Rochester.

Dutton, D. G., \& Holtzworth-Munroe, A. (1997b). The role of early trauma in males who assault their wives. In D. C. S. L. Toth (Ed.), Rochester symposium on developmental psychopathology: Developmental perspectives on trauma-theory, research and intervention. Rochester, N.Y.: University of Rochester press.

Dutton, D. G., \& Nicholls, T. L. (2005). The gender paradigm in domestic violence research and theory: Part 1 . The conflict of theory and data. Aggression and Violent Behavior, 10(6), 680-714.

Dutton, D. G., Saunders, K., Starzomski, A., \& Bartholomew, K. (1994). Intimacy anger and insecure attachment as precursors of abuse in intimate relationships. Journal of Applied Social Psychology, 24(15), 1367-1386.

Dutton, D. G., \& Sonkin, D. J. (2003). Intimate violence: Contemporary treatment innovations. Binghampton, NY: Haworth Press.

Dutton, D. G., \& Starzomski, A. (1993). Borderline personality in perpetrators of psychological and physical abuse. Violence and Victims, 8(4), 327-337.

Dutton, D. G., \& Starzomski, A. (1994). Psychological differences between court-referred and self-referred wife assaulters. Criminal Justice and Behavior: An Internatioanl Journal, 21(2), 203-222.

Dutton, D. G., Starzomski, A., \& Ryan, L. (1996). Antecedents of borderline personality organization in wife assaulters. Journal of Family Violence, $11(2), 113-132$.

Dutton, D. G., Swanson, C. H., van Ginkel, C., \& Starzomski, A. J. (in press). The role of shame and guilt in the intergenerational transmission of abusiveness. Unpublished manuscript, Vancouver, British Columbia.

Eckhardt, C. I., Barbour, K. A., \& Davis, G. C. (1998). Articulated thoughts of martially violent and nonviolent men during anger arousal. Journal of Consulting and Clinical Psychology, 66(2), 259-269.

Eckhardt, C. I., Barbour, K. A., \& Stuart, G. L. (1997). Anger and hostility in martially violent men: Conceptual distinctions, measurement issues and literature review. Clinical Psychology Review, 17(4), 333-358.

Egland, B. (1993). A history of abuse is a major risk factor for abusing in the next generation. In R. J. Gelles, \& D. L. Loeske (Eds.), Current controversies on family violence (pp. 197-208). Newbury park: Sage.

Ehrensaft, M. K., Cohen, P., \& Johnson, J. G. (in press). Development of personality disorder symptoms and the risk of partner violence. Journal of Abnormal Psychology.

Ehrensaft, M. K., Moffitt, T. E., \& Caspi, A. (2004). Clinically abusive relationships in an unselected birth cohort: Men's and women's participation and developmental antecedents. Journal of Abnormal Psychology, 113(2), 258-270.

Elliott, F. (1977). The neurology of explosive rage: The episodic dyscontrol syndrome. In M. Roy (Ed.), Battered women: A psychosociological study of domestic violence New York: Van Nostrand.

Fagan, J. (1989). Cessation of family violence: Deterrence and dissuasion. In L. Ohlin, \& M. Tonry (Eds.), Family violence Chicago: University of Chicago Press.

Fagan, J. (1996). The criminalization of domestic violence. Washington, D.C.: National Institute of Justice.

Fagan, J., Stewart, D. K., \& Hansen, K. V. (1983). Violent men or violent husbands? Background factors and situational correlates. In D. Finkelhor, R. J. Gelles, G. Hotaling, \& M. A. Straus (Eds.), The dark side of families: Current family violence research (pp. 49-68). Beverley Hills: Sage.

Faludi, S. (1981). Backlash: The undeclared war against American women. New York: Doubleday.

Feder, L., \& Forde, D. R. (1999). A test of efficacy of court mandated counseling for convicted misdemeanor domestic violence offenders: Results from the Brouward experiment. Paper presented at the International Family Violence Conference, Durham, NH.

Feld, S. L., \& Straus, M. (1990). Escalation and desistance from wife assault in marriage. In M. A. Straus, \& R. J. Gelles (Eds.), Physical violence in American families. New Brunswick, NJ: Transaction Publishers.

Ferrante, A., Morgan, F., Indermaur, D., \& Harding, R. (1996). Measuring the extent of domestic violence. Perth, Australia: Hawkins Press.

Follingstad, D. R., Bradley, R. G., Helff, C. M., \& Laughlin, J. E. (2002). A model for predicting dating violence: Anxious attachment, angry temperament and need for relationship control. Violence and Victims, 17(1), 35-47.

Follingstad, D. R., DeHart, D. D., \& Green, E. P. (2004). Psychologists' judgments of psychologically aggressive actions when perpetrated by a husband versus a wife. Violence and Victims, 19(4), 435-452.

Ford, D. A., \& Regoli, M. J. (1993). The criminal prosecution of wife assaults: Process, problems, and effects. In N. Z. Hilton (Ed.), Legal responses to wife assault: Current trends and evaluation (pp. 127-164). Newbury Park, CA: Sage.

Garner, J. H., Fagan, J. A., \& Maxwell, C. D. (1995). Published findings from the spouse assault replication program: A critical review. Journal of Quantitative Criminology, 11, 3-28.

Garner, J. H., \& Maxwell, C. D. (2000). What are the lessons of the police arrest studies? Journal of Aggression, Maltreatment and Trauma, 4, 83-114.

Gelles, R. J. (1996). Constraints against family violence: How well do they work? In E. S. Buzawa, \& C. G. Buzawa (Eds.), Domestic violence: The changing criminal justice response. Westport, C.T: Auburn House.

Gelles, R. (2001). Standards for men who batter? Not yet. Journal of Aggression, Maltreatment and Trauma, 5(2), 11-20.

Gelles, R. J., \& Straus, M. A. (1988). Intimate violence: The causes and consequences of abuse in the American family. New York: Simon and Schuster. Georgia, S. O. (2002). Family violence intervention provider statute. Athens, Georgia: State of Georgia.

Gottman, J. M., Jacobson, N. S., Rushe, R., Shortt, J. W., Babcock, J., La Taillade, J. J., et al. (1995). The relationship between heart rate reactivity, emotionally aggressive behavior and general violence in batterers. Journal of Family Psychology, 9(3), 227-248. 
Grove, W. M., \& Meehl, P. E. (1996). Comparative efficiency of informal (subjective, impressionistic) and formal (mechanical, algorithmic) prediction procedures: The clinical-statistical controversy. Psychology, Public Policy, and Law, 2, 293-323.

Hamberger, K., \& Hastings, J. E. (1991). Personality correlates of men who batter and non-violent men: Some continuities and discontinuities. Journal of Family Violence, 6(2), 131-147.

Hamberger, L. K., Lohr, J. M., Bonge, D., \& Tolin, D. F. (1996). A large empirical typology of male spouse abusers and its relationship to dimensions of abuse. Violence and Victims, 11, 277-292.

Hanson, K., Cadsky, O., Harris, A., \& Lalonde, C. (1997). Correlates of battering among 997 men: Family history, adjustment and attitudinal differences. Violence and Victims, 12(3), 191-208.

Healey, K., Smith, C., \& O’Sullivan, C. (1998). Batterer intervention: Program approaches and criminal justice strategies. Washington, D.C.: National Institute of Justice.

Hirshell, J. D., \& Hutchinson, I. W. (1992). Female spouse abuse and the police response: The Charlotte, North Carolina experiment. Journal of Criminal Law and Criminology, 83(1), 73-119.

Holtzworth-Munroe, A., Bates, L., Smutzler, N., \& Sandin, E. (1997). A brief review of the research on husband violence: Part I. Maritally violent versus nonviolent men. Aggression and Violent Behavior, 2(1), 65-99.

Holtzworth-Munroe, A., \& Stuart, G. L. (1994). Typologies of male batterers: Three subtypes and the differences among them. Psychological Bulletin, 116(3), 476-497.

Holtzworth-Munroe, A., Stuart, G. L., \& Hutchinson, G. (1997). Violent versus nonviolent husbands: Differences in attachment patterns, dependency, and jealousy. Journal of Family Psychology, 11, 314-331.

Hotaling, G., \& Buzawa, E. S. (2003). Forgoing criminal justice assistance: The non-reporting of new incidents of abuse in a court sample of domestic violence victims. Washington, DC: National Institute of Justice. National Criminal Justice Reference Service.

Howard, M. O., McMillen, C. J., \& Pollio, D. (2003). Research on social work practice. Council on Social Work Education, 13(2), 234-259.

Jacobson, N. S., \& Gottman, J. (1998). When men batter women: New insights into ending abusive relationships. New York: Simon and Schuster.

Jacobson, N. S., Gottman, J. M., Gortner, J. M., Berns, S., \& Shortt, J. W. (1996). Psychological factors in the longitudinal course of battering: When do the couples split up? When does the abuse decrease? Violence and Victims, 11(4), 371-392.

Jacobson, N. S., Gottman, J. M., Waltz, J., Rushe, R., Babcock, J., \& Holtzworth-Munroe, A. (1994). Affect, verbal content, and psychophysiology in the arguments of couples with a violent husband. Journal of Consulting and Clinical Psychology, 62(5), 982-988.

Jaffe, P., Lemon, N., \& Poisson, S. E. (2003). Child custody and domestic violence: A call for safety and accountability. Thousand Oaks: Sage.

Janis, I. L. (1982). Groupthink (2nd ed.). Boston: Houghton-Mifflin.

Johnson, M. P. (1995). Patriarchal terrorism and common couple violence: Two forms of violence against women. Journal of Marriage and the Family, 57, 283-294.

Johnson, M. P., \& Leone, J. M. (2005). The differential effects of intimate terrorism and situational couple violence: Findings from the National Violence Against Women Survey. Journal of Family Issues, 26(3), 322-349.

Johnston, J. R., \& Roseby, V. (1997). In the name of the child: A developmental approach to understanding and helping children of conflicted and violent divorces. New York: Free Press.

Kahneman, D., Slovic, P., \& Tversky, A. (1982). Judgment under uncertainty: Heuristics and biases. London: Cambridge University Press.

Kimmel, M. (2002). "Gender symmetry" in domestic violence. Violence Against Women, 8(11), 1332-1363.

Laroche, D. (2005). Aspects of the context and consequences of domestic violence-Situational couple violence and intimate terrorism in Canada in 1999. Quebec City: Government of Quebec.

Leonard, K. E., \& Roberts, L. J. (1998). The effects of alcohol on the marital interactions of aggressive and nonaggressive husbands and their wives. Journal of Abnormal Psychology, 107(4), 602-615.

Leonard, K. E., \& Senchak, M. (1993). Alcohol and premarital aggression among newlywed couples. Journal of Studies on Alcohol, 11, 96-108.

Levenson, R. W., \& Gottman, J. M. (1983). Marital interaction: Physiological linkage and affective exchange. Journal of Personality and Social Psychology, 45(3), 587-597.

Levesque, D. (1998). Violence desistance among battering men: Existing intervention and the application of the transtheoretical model for change. Unpublished manuscript, Kingston, Rhode Island.

Lie, G., Schilit, R., Bush, J., Montague, M., \& Reyes, L. (1991). Lesbians in currently aggressive relationships: How frequently do they report aggressive past relationships? Violence and Victims, 6(2), 121-135.

Lord, C., Ross, L., \& Lepper, M. R. (1979). Biased assimilation and attitude polarization: The effects of prior theories and subsequently considered evidence. Journal of Personality and Social Psychology, 37, 2098-2109.

Luborsky, L. (1984). Principles of psychoanalytic therapy: A manual for supportive-expressive treatment. New York: Basic Books.

Magdol, L., Moffitt, T. E., Caspi, A., Newman, D. L., Fagan, J., \& Silva, P. A. (1997). Gender differences in partner violence in a birth cohort of 21-year-olds: Bridging the gap between clinical and epidemiological approaches. Journal of Consulting and Clinical Psychology, 65(1), $68-78$.

Maiuro, R. D., Cahn, T. S., Vitaliano, P. P., Wagner, B. C., \& Zegree, J. B. (1988). Anger, hostility and depression in domestically violent versus generally assaultive men and nonviolent control subjects. Journal of Consulting and Clinical Psychology, 56, 17-23.

Maiuro, R. D., \& Eberle, J. A. (in press). State standards for domestic violence perpetrator treatment: Current status, trends and recommendations. Violence and Victims.

Maiuro, R. D., Hagar, T. S., Lin, H., \& Olson, N. (2001). Are current state standards for domestic violence perpetrator treatment adequately informed by research? A question of questions. Journal of Aggression, Maltreatment and Trauma, 5(2), 21-44.

Margolin, G., John, R. S., \& Gleberman, L. (1989). Affective responses to conflictual discussions in violent and non-violent couples. Journal of Consulting and Clinical Psychology, 56(1), 24-33. 
Markowitz, F. (2003). Socioeconomic disadvantage and neighborhood control as explanatory mechanisms. Aggression and Violent Behavior, 8(2), 145-154.

McClelland, D. (1975). Power: The inner experience. New York: Halstead.

McCloskey, L. A., Figueredo, A. J., \& Koss, M. P. (1995). The effects of systematic family violence on children's mental health. Child development, $66,1239-1261$.

Mechem, C. C., Shofer, F., Reinhard, S. S., Hornig, S., \& Datner, E. (1999). History of domestic violence among male patients presenting to an urban emergency department. Academic Emergency Medicine, 6, 786-791.

Meloy, J. R. (1992). Violent attachments. Northvale, N.J.: Jason Aronson.

Miller, N. (2004). Domestic Violence Legislation. 2005, from www.ilj.org/dv/Papers/DV_Legislation-3.pdf

Mills, L. G. (1999). Killing her softly: Intimate abuse and the violence of state intervention. Harvard Law Review, 113(2), 551-613.

Mills, L. G. (2003). Insult to injury: Rethinking our response to intimate abuse. Princeton, NJ: Princeton University Press.

Moffitt, T. E., Caspi, A., Rutter, M., \& Silva, P. A. (2001). Sex differences in antisocial behavior. Cambridge: Cambridge University Press.

Monet, D. R., Sullivan, T. J., \& DeJong, C. R. (2005). Applied social research: Tool for the social sciences. Fort Wrth, Texas: Harcourt College Publishers.

Moos, R. H. (2005). Iatrogenic effects of psychosocial interventions for substance use disorders: Prevalence, predictors, prevention. Addiction, $100(5), 595-604$.

Morse, B. J. (1995). Beyond the conflict tactics: Assessing gender differences in partner violence. Violence and Victims, 4, $251-271$.

Newmark, L., Hartnell, A., \& Salem, P. (1995). Domestic violence and empowerment in custody and visitation cases. Family and Conciliation Courts review, 33, 30-62.

O'Leary, K. D., Heyman, R., \& Neidig, P. H. (1999). Treatment of wife abuse: A comparison of gender-specific and couple approaches. Behavior Assessment, 30, 475-505.

Pence, E., \& Paymar, M. (1993). Education groups for men who batter: The Duluth model. New York: Springer.

Pimlott-Kubiak, S., \& Cortina, L. M. (2003). Gender, victimization, and outcomes: Reconceptualizing risk. Journal of Consulting and Clinical Psychology, 71(3), 528-539.

Programs, O. O. C. J. (2004-2005). Compettitve Grant Application.

Putallaz, M., \& Bierman, K. L. (2004). Aggression, antisocial behavior and violence amongst girls. New York: Guilford.

Reitzel-Jaffe, D., \& Wolfe, D. (2001). Predictors of relationship abuse among young men. Journal of Interpersonal Violence, 16(2), 99-115.

Reynolds, P. D. (1971). A primer in theory construction. Indianapolis: Bobbs-Merrill.

Robins, L. N., Helzer, J. E., Cottler, L. B., Works, J., Goldring, E., McEvoy, L., et al. (1987). The diagnostic interview schedule version III-A training manual. St. Louis: Veterans Administration.

Rounsaville, B. (1978). Theories in marital violence: Evidence from a study of battered women. Victimology: An International Journal, 3(1-2), 11-31.

Rouse, L. P., Breen, R., \& Howell, M. (1988). Abuse in intimate relationships: A comparison of married and dating college students. Journal of Interpersonal Violence, 3(4), 414-429.

Saunders, D. G. (1988). Wife abuse, husband abuse or mutual combat: A feminist perspective on the empirical findings. In K. Yllo, \& M. Bograd (Eds.), Feminist perspectives on wife assault (pp. 90-113). Newbury Park: Sage.

Schore, A. N. (2003a). Affect dysregulation and the disorders of the self. New York: Norton.

Schore, A. N. (2003b). Affect regulation and the repair of the self. New York: Norton.

Schwartz, M. D. (1987). Gender and injury in spouse assault. Sociological Focus, 20(1), 61-76.

Serbin, L., Stack, D., De Genna, N., Grunzeweig, N., Temcheff, C. E., Schwartzmann, A. E., et al. (2004). When aggressive girls become mothers. In M. Putallaz, \& K. L. Bierman (Eds.), Aggression, antisocial behavior and violence among girls. New York: The Guilford Press.

Shepard, M. (1987). Interventions with men who batter: An evaluation of a domestic abuse program. Paper presented at the Third National Conference on Domestic Violence, University of New Hampshire.

Shepard, M. (1992). Predicting batterer recidivism five years after community intervention. Journal of Family Violence, 7(3), $167-178$.

Sherman, L. W. (1993). Defiance, deterrence, and irrelevance: A theory of the criminal sanctions. Journal of Research in Crime and Delinquency, 30, 44-473.

Sherman, L. W., \& Berk, R. A. (1984). The specific deterrent effects of arrest for domestic assault. American Sociological Review, 49, $261-272$.

Sherman, L. W., Schmidt, J. D., Rogan, D. P., Smith, D. A., Gartin, P. R., Cohn, E. G., et al. (1992). The variable effects of arrest of criminal careers: The Milwaukee domestic violence experiment. Journal of Criminal Law and Criminology, 83(1), 137-169.

Siegel, J. M. (1986). The multidimensional anger inventory. Journal of Personality and Social Psychology, 5(1), $191-200$.

Simon, T. R., Anderson, M., Thompson, M. P., Crosby, A. E., Shelley, G., \& Sacks, J. J. (2001). Attitudinal acceptance of intimate partner violence among U.S. adults. Violence and Victims, 16(2), 115-126.

Skeem, J., Schubert, C., Stowman, S., Beeson, S., Mulvey, E. P., Gardner, W., et al. (2005). Gender and risk assessment accuracy: Understanding women's potential violence. Law and Human Behavior, 29(2), 173-186.

Smith, M. (1990). Patriarchal ideology and wife beating: A test of feminist hypothesis. Violence and Victims, 5(4), $257-273$.

Sonkin, D. J. (2005). Attachment theory and psychotherapy. The Therapist, January/ February, 47-62.

Sorenson, S. B., \& Taylor, C. A. (2005). Female aggression toward male intimate partners: An examination of social norms in a community-based sample. Psychology of Women Quarterly, 29, 79-96.

Sroufe, A., Egeland, B., Carlson, E. A., \& Collins, W. A. (2005). The development of the person. New York: Guilford.

Stets, J., \& Straus, M. A. (1992a). Gender differences in reporting marital violence. Physical violence in American families (pp. 151-166). New Brunswick, N.J.: Transaction Publishers.

Stets, J., \& Straus, M. A. (1992b). The marriage license as a hitting license. Physical violence in American families. New Brunswick, N.J.: Transaction Publishers. 
Stith, S. M., Rosen, K. H., \& McCollum, E. E. (2003). Effectiveness of couples treatment for spouse abuse. Journal of Marital and Family Therapy, 29, 407-426.

Stith, S. M., Smith, D. B., Penn, C. E., Ward, D. B., \& Tritt, D. (2004). Intimate partner physical abuse perpetration and victimization risk factors: A meta-analysis review. Aggression and Violent Behavior, 10(1), 65-98.

Straus, M. A. (1973). A general systems theory approach to a theory of violence between family members. Social Science Information, 12(3), $105-125$.

Straus, M. A. (1992). Measuring intrafamily conflict and violence: The conflict tactics scale. In M. A. Straus, \& R. J. Gelles (Eds.), Physical violence in American families New Brunswick, N.J.: Transaction Publishers.

Straus, M. A. (1999). The controversy over domestic violence by women: A methodological, theoretical and sociology of science analysis. In X. Arriaga, \& S. Oskamp (Eds.), Violence in intimate relationships (pp. 17-44). Thousand Oaks: Sage.

Straus, M. A., \& Gelles, R. J. (1992). How violent are American families: Estimates from the national family violence resurvey and other surveys. In M. A. Straus, \& R. J. Gelles (Eds.), Physical violence in american families (pp. 95-108). New Brunswick, N.J.: Transaction.

Straus, M. A., Gelles, R. J., \& Steinmetz, S. (1980). Behind closed doors: Violence in the American family. Garden City, N.Y.: Anchor Press/ Doubleday.

Sugarman, D., \& Boney-McCoy, S. (1999). The art of reviewing research. In S. K. Ward, \& D. Finkelstein (Eds.), Program evaluation and family violence research. New York: Haworth Press.

Tjaden, P., \& Thoennes, N. (1998). Prevalence, incidence and consequences of violence against women: Findings from the National Violence Against Women Survey. Washington, D.C.: US Department of Justice.

Trocme, N. (2001). Canadian incidence study of reported child abuse and neglect (No. H49-151/2000E). Ottawa: Health Canada.

Turner, C. (1986). The structure of sociological theory. Chicago: Dorsey Press.

Tweed, R., \& Dutton, D. G. (1998). A comparison of impulsive and instrumental subgroups of batterers. Violence and Victims, 13(3), 217-230.

Walker, L. (1989). Psychology and violence against women. American Psychologist, 44(4), 695-702. 